\title{
Optimal DC Voltage and Current Control of an LCC HVDC System to Improve Real-Time Frequency Regulation in Rectifier- and Inverter-Side Grids
}

\author{
Do-Hoon Kwon, Member, IEEE and Young-Jin Kim, Member, IEEE, and Oriol Gomis-Bellmunt, Senior Member, IEEE
}

\begin{abstract}
High-voltage direct-current (HVDC) systems for constant or intermittent power delivery have recently been developed further to support grid frequency regulation (GFR). This paper proposes a new control strategy for a line-commutated converter-based (LCC) HVDC system, wherein the dc-link voltage and current are optimally regulated to improve real-time GFR in both rectifier- and inverter-side grids. A dynamic model of an LCC HVDC system is developed using the dc voltage and current as input variables, and is integrated with feedback loops for inertia emulation and droop control. A linear quadratic Gaussian (LQG) controller is also designed for optimal secondary frequency control, while mitigating conflict between the droop controllers of HVDC converters. An eigenvalue analysis is then conducted, focusing on the effects of model parameters and controller gains on the proposed strategy. Simulation case studies are performed using the models of a real HVDC system and a CIGRE benchmark system. The case study results confirm that the proposed strategy enables the HVDC system to improve GFR, in coordination with generators in both-side grids, by exploiting the fast dynamics of HVDC converters. The proposed strategy is also effective under various conditions for the LQG parameters, inertia emulation, and droop control.
\end{abstract}

Index Terms - dc voltage and current, droop control, frequency regulation, high-voltage direct-current system, line-commutated converter, linear quadratic Gaussian, inertia emulation.

\section{NOMENCLATURE}

$\begin{array}{ll}\text { A. Acronyms } & \\ \text { GFR } & \text { grid frequency regulation } \\ \text { HVDC } & \text { high-voltage direct-current } \\ \text { IPM } & \text { inverse power modeling } \\ \text { LCC } & \text { line-commutated converter-based } \\ \text { LQG } & \text { linear quadratic Gaussian } \\ \text { PFC } & \text { primary frequency control } \\ \text { SFC } & \text { secondary frequency control } \\ \text { RES } & \text { renewable energy source } \\ \text { VSC } & \text { voltage-source converter-based } \\ \text { WF } & \text { wind farm } \\ B . S e t s \text { and } & \text { Indices } \\ a, b, c & \text { coefficients for small-signal modeling of HVDC } \\ & \text { system } \\ m, n & \text { coefficients for estimation of } \Delta I_{d c i} / \Delta I_{d c i} r e f \text { and } \\ r, i & \Delta V_{d c r} / \Delta V_{d c r} \text { ref } \\ r e f, 0 & \text { subscripts for variables and parameters related to the } \\ (x, \beta, H) & \text { HVDC rectifier and inverter } \\ & \text { subscripts for reference and nominal values }\end{array}$

Manuscript received Oct. 12, 2019 (corresponding author: Y. Kim).

D. H. Kwon is with Korea Electrotechnology Research Institute (KERI), Uiwang-si, Gyeonggi-do, 16029, Korea (e-mail: dhkwon@keri.re.kr).

Y. Kim is with the Department of Electrical Engineering, Pohang University of Science and Technology, Pohang, Gyungbuk 37673, Korea (e-mail: powersys@postech.ac.kr).

O. Gomis-Bellmunt is with the Centre d'Innovacio Tecnologica en Convertidors Estatics i Accionaments, Departament d'Enginyeria Electrica, Universitat Politecnica de Catalunya, Barcelona 08028, Spain (oriol.gomis@upc.edu)
E subscript for an augmented small-signal model

\section{HVDC System}

$V_{c r}, I_{c i} \quad \mathrm{dc}$ voltage and current controlled via inertia $V_{d c} \quad$ dc-link voltage

$V_{d c r}, V_{d c i} \quad$ dc voltages of the rectifier and inverter

$I_{c} \quad$ charging current of the dc-link capacitor

$I_{d c r}, I_{d c i} \quad \mathrm{dc}$ currents of the rectifier and inverter

$P_{d c r}, P_{d c i} \quad \mathrm{dc}$ power transfer of the rectifier and inverter

$R, L, C \quad$ dc-link resistance, inductance, and capacitance

$N \quad$ number of bridges connected within series in HVDC

converters

$T R_{r}, T R_{i} \quad$ converter transformer tap ratios

$V_{\text {drop }} \quad \mathrm{dc}$ voltage drop between the rectifier and inverter

$V_{l r}, V_{l i} \quad$ secondary voltages of the converter transformers

$X_{c r}, X_{c i} \quad$ reactance of the converter transformers

$\alpha, \gamma \quad$ firing and extinction angles

$\mu_{r}, \mu_{i} \quad$ overlap angles of the switching valves

$T_{f r}, T_{f i} \quad$ time constants of the low pass filters

$T_{k}, T_{d c f 1,2}$ time constants of the dc link and dc harmonic filters

$T_{r}, T_{i} \quad$ equivalent time constants of the rectifier and inverter

$K_{r}, K_{i} \quad$ gains for de voltage-power droop control

$R_{r}, R_{i} \quad$ gains for frequency-power droop control

$V_{r}, V_{i} \quad$ inertia emulation gains

$k_{p r}, k_{i r} \quad$ PI controller gains for $V_{d c r}$ control

$k_{p i}, k_{i i} \quad$ PI controller gains for $I_{d c i}$ control

$K P_{r, i}, K I_{r, i} \quad$ PI controller gains for the SFCs of the rectifier and inverter

D. Rectifier- and Inverter-Side Grids

$f_{r}, f_{i} \quad$ frequencies of both-side grids

$D_{r}, D_{i} \quad$ load damping coefficients of both-side grids

$M_{r}, M_{i} \quad$ moments of inertia of both-side grids

$P_{g r}, P_{g i} \quad$ power outputs of conventional generators

$P_{\text {gr }}$ ref, $\quad$ reference power outputs of conventional generators

$P_{\text {gi } r e f}$

$P_{l r}, P_{l i}$

$P_{t r}, P_{t i}$

load demand in both-side grids

steam turbines

$P_{w} \quad$ wind power generation

$T_{g r}, T_{g i} \quad$ time constants of governors

$T_{t r}, T_{t i} \quad$ time constants of steam turbines

$R_{g r}, R_{g i} \quad$ gains for frequency-power droop control

E. Coordinated Control of the HVDC System and Generators

$\mathbf{A}, \mathbf{B}_{\mathbf{r}}, \mathbf{B}_{\mathbf{w}}, \quad$ coefficient matrices of the small-signal model of the C

$\mathbf{A}_{\mathbf{E}}, \mathbf{B}_{\mathrm{rE}}$,

$B_{w E}, C_{E}$

$\mathbf{A}_{\mathbf{s}}$

$\mathbf{X}, \mathbf{Y}$ HVDC system and generators

coefficient matrices of the augmented small-signal model of the HVDC system and generators

$\mathbf{Y}, \mathbf{Y}$ sub-matrix in $\mathbf{A}_{\mathbf{E}}$

$\mathbf{X}_{\mathrm{E}}, \mathbf{Y}_{\mathbf{E}}$

$\widehat{\mathrm{X}_{\mathrm{E}}}$

$\mathbf{d}, \mathbf{n} \quad$ input and output disturbances states and outputs of the small-signal model of the HVDC system and generators

$\mathbf{r}, \mathbf{w} \quad$ controllable and uncontrollable inputs of the smallsignal model of the HVDC system and generators 

$\mathbf{K}$
$\mathbf{Q}, \mathbf{R}$
LQG gain matrix minimizing the cost function $J$
V
$J$
$L_{p}, L_{c}$
$n, n_{V}, n_{f}$

LCC HVDC system. For example, in [9], the hourly optimal power flow was calculated by reference to the fast-acting corrective control of an LCC HVDC system when the HVDC bi-pole block resulted in large frequency deviations in the sending- and receiving-end grids. In [10], a four-state nonlinear model was presented to determine the interaction between the rectifier- and inverter-side grids and develop HVDC firing angle controllers and a WF droop controller. Considering inter-grid coupling, optimal control schemes can be adopted to better utilize HVDC systems. For example, in [11] and [12], linear quadratic regulators (LQRs) were used to reduce variation in the voltage and rotor angle, respectively, and hence enhance the damping of inter-area power oscillations; however, the HVDC system models were relatively simple and droop controllers were not considered.

In [9]-[11], the dc-link voltage of the HVDC system was simply maintained at the rated value. In practice, LCC HVDC converters can operate under normal conditions, with short-term under- and over-voltages of the dc link, as reported in field test results [13], [14]. Recently, a few studies have explored time-varying control of the dc-link voltage, mainly for voltage-source converter-based (VSC) HVDC systems. For example, in [15], a VSC HVDC system was controlled with the operating range of the dc-link voltage varying from approximately $0.98 \mathrm{pu}$ to $1.04 \mathrm{pu}$ for a $5 \%$ variation in load demand. In [16], the energy stored in the dc link was combined with the frequency support capabilities of wind turbines. Time-varying control of the dc-link voltage can also be applied to LCC HVDC systems. For example, in [17] and [18], dc-link voltage control improved the capabilities of LCC HVDC systems principally in the contexts of short-term power transfer and reactive power control, respectively.

This paper proposes a new control strategy for an LCC HVDC system, in which the optimal control of dc-link voltage and current is achieved in real time to improve GFR in both the rectifier- and inverter-side networks. A small-signal model of the HVDC system is developed using the dc voltage and current references as input variables, and validated via comparison with the comprehensive models of a real HVDC system and a CIGRE benchmark system. The HVDC converters support real-time GFR via primary (PFC) and secondary frequency control (SFC). For PFC, the converters are integrated with feedback loops for frequency- and dc voltage-power droop control, and also allow inertial response emulation. A linear quadratic Gaussian (LQG) controller, combining an LQR with

Recently, GFR has been considered on both sides of the

TABLE I. SPECIFICATIONS, MODELS, AND GRID-LEVEL CONTROLLERS OF LCC HVDC SYSTEMS

\begin{tabular}{|c|c|c|c|c|c|c|c|c|c|c|c|c|c|c|c|}
\hline \multirow[b]{2}{*}{ Ref. } & \multicolumn{4}{|c|}{ (a) Specifications } & \multicolumn{6}{|c|}{ (b) Modelling } & \multicolumn{5}{|c|}{ (c) Grid-level controllers } \\
\hline & $\begin{array}{c}P_{d c 0} \\
{[\mathrm{MW}]}\end{array}$ & $\begin{array}{l}V_{d c 0} \\
{[\mathrm{kV}]}\end{array}$ & $V_{d c}$ & $\begin{array}{l}\text { varying } \\
\text { power }\end{array}$ & $\begin{array}{r}\mathrm{il} \\
\text { refe }\end{array}$ & $\begin{array}{l}\text { ut } \\
\text { nces }\end{array}$ & output & converters & dc link & filters & objective & $\begin{array}{l}\text { target } \\
\text { grids }\end{array}$ & $\begin{array}{l}\text { inertial } \\
\text { response }\end{array}$ & droop & SFC \\
\hline Proposed & 150 & 184 & varying & $P$ & $V_{d c r}$ & $I_{d c i}$ & $V_{d c,} P_{d c i, r}$ & avg. & $\mathrm{T}$ & $\mathrm{ac}, \mathrm{dc}$ & opt. GFR & both & $\mathrm{O}$ & $\mathrm{O}$ & LQG \\
\hline [5] & 1000 & 500 & constant & $P$ & $I_{d c r}$ & & $I_{d c r}$ & switch & RL circuit & ac & GFR & rec. & & $\mathrm{O}$ & PI \\
\hline [6] & 500 & 500 & & & $P_{d c r}$ & $\gamma$ & $P_{d c r}$ & avg. & & & GFR & inv. & $\mathrm{O}$ & $\mathrm{O}$ & \\
\hline [7] & 1000 & 500 & & & $f_{r}$ & $\gamma$ & & avg. & $\mathrm{T}$ & ac & GFR & rec. & $\mathrm{O}$ & & \\
\hline$[8]$ & 100 & 200 & & & $P_{d c r}$ & $I_{d c i}$ & $V_{d c r}, I_{d c i}$ & avg. & $\mathrm{T}$ & $\mathrm{dc}$ & GFR & inv. & & $\mathrm{O}$ & PID \\
\hline [10] & 1000 & 500 & & & $f_{r}$ & $\gamma$ & $P_{d c i}$ & avg. & $\mathrm{T}$ & & GFR & both & & $\mathrm{O}$ & \\
\hline [11] & 50 & 100 & & & $I_{d c r}$ & $V_{d c i}$ & $P_{a c r}, Q_{a c i}$ & injection & $\mathrm{T}$ & & opt. damping & both & & & LQG \\
\hline [12] & - & - & varying & & $I_{d c r}$ & $V_{d c i}$ & $P_{a c i, r}, Q_{a c i}$ & injection & $\mathrm{T}$ & & opt. damping & both & & & LQG \\
\hline [16] & 300 & 300 & & & $P_{d c r}$ & $V_{d c i}$ & $P_{d c r}$ & switch & $\Pi$ & & GFR & inv. & $\mathrm{O}$ & $\mathrm{O}$ & PI \\
\hline [17] & 150 & 184 & & & $V_{d c r}$ & $I_{d c i}$ & $P_{d c i}$ & avg. & $\mathrm{T}$ & & GFR & inv. & & $\mathrm{O}$ & PI \\
\hline [18] & 250 & 500 & & $P, Q$ & $P_{d c r}$ & $Q_{a c i}$ & $P_{d c r}, Q_{a c i}$ & switch & $\mathrm{T}$ & ac & voltage reg. & inv. & & & \\
\hline
\end{tabular}




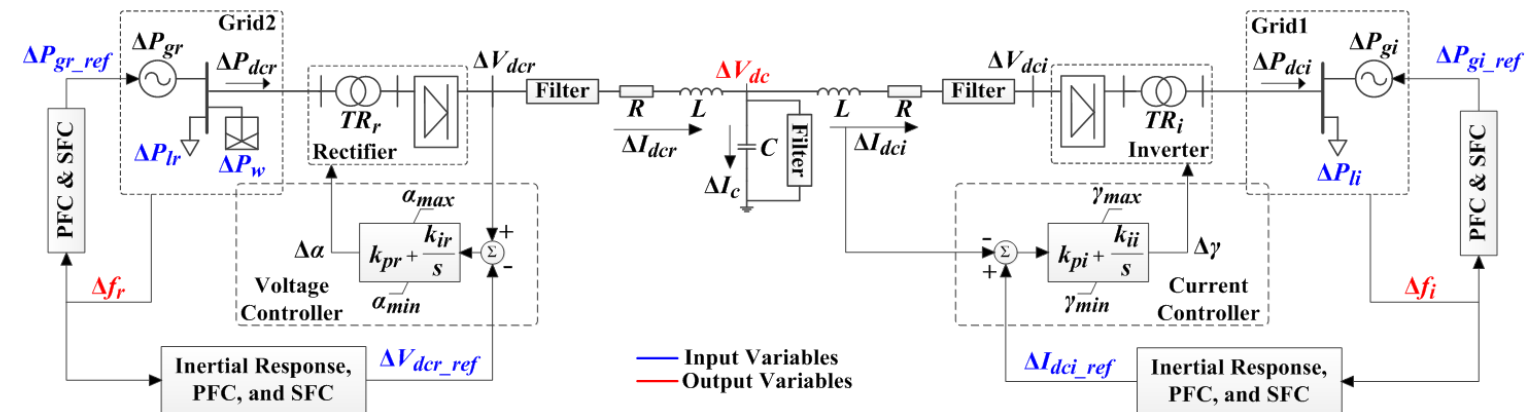

Fig. 1. A schematic diagram of the proposed control strategy for an LCC HVDC system to support real-time GFR in the rectifier- and inverter-side ac networks.

a Kalman filter, is also incorporated into the feedback loops to achieve optimal SFC, minimizing the weighted sum of instantaneous and accumulated deviations of the dc-link voltage and grid frequencies in the rectifier- and inverter-side grids. An eigenvalue analysis is then conducted to evaluate the performance of the proposed control strategy with variation in the model parameters and controller gains of the HVDC system. Simulation case studies are also carried out to demonstrate that the proposed strategy effectively improves real-time GFR in the context of variation in load demand and WF power generation under various conditions on the LQG weighting factors and the inertia emulation and droop control approaches.

The main contributions of this paper are summarized below: - To the best of our knowledge, this is the first study reporting optimal dc voltage and current control of an LCC HVDC system for real-time GFR of both rectifier- and inverter-side grids using an LQG controller.

- The methods for inertial response emulation and frequencyand dc voltage-power droop control are integrated to exploit the fast responses of HVDC converters. The LQG controller resolves conflicts between the droop controllers.

- A small-signal model is implemented whereby the dc voltage and current can be separately controlled at distinct HVDC terminals. The small-signal model is simple, but successfully reflects dynamic variations in dc voltage, current, and power.

- The effectiveness of the proposed optimal control strategy is verified using the models of a real HVDC system and a CIGRE benchmark system as the load demand, LQG parameters, and PFC type vary.

\section{DYNAMIC MODEL OF LCC HVDC SYSTEM FOR GFR VIA THE CONTROL OF DC-LINK VOLTAGE AND CURRENT}

Fig. 1 shows a schematic diagram of the proposed strategy, in which an LCC HVDC system supports real-time GFR in the rectifier- and inverter-side grids. The rectifier and inverter use the same architecture and inner feedback loops to control $\Delta V_{d c r}$ and $\Delta I_{d c i}$, respectively. The dc link is characterized using a T-model, where $\Delta P_{d c r}$ flows into the rectifier and $\Delta P_{d c i}$ flows from the inverter. Under normal grid conditions, the off-nominal frequencies $\Delta f_{i}$ and $\Delta f_{r}$ reflect the load demand variations $\Delta P_{l i}$ and $\Delta P_{l r}$ in the both-side grids and the intermittent power outputs $\Delta P_{w}$ of the WF in the rectifier-side grid. The proposed strategy focuses on mitigating $\Delta f_{i}$ and $\Delta f_{r}$ via optimal control of $\Delta V_{d c r}$ and $\Delta I_{d c i}$ before frequency deviations become severe enough to adversely affect ac network operations. Analysis of the proposed strategy under abnormal conditions (e.g., ac line faults and commutation failures) will be conducted in future work.

\section{A. Dynamic Model of LCC HVDC System}

The dc-link voltage, current, and power at the terminals of the rectifier and inverter can be represented [19] as:

$$
\begin{aligned}
V_{d c x} & =\frac{3 \sqrt{2} N}{\pi T R_{x}} V_{l x} \cos \beta-\frac{3 X_{c x} N}{\pi} I_{d c x}, \\
I_{d c x} & =\frac{V_{l x}}{\sqrt{2} X_{c x} T R_{x}}\left(\cos \beta-\cos \left(\beta+\mu_{x}\right)\right), \\
P_{d c x} & =V_{d c x} I_{d c x}, \\
& =\frac{3 N}{4 \pi X_{c x}}\left(\frac{V_{l x}}{T R_{x}}\right)^{2}\left\{\cos (2 \beta)-\cos 2\left(\beta+\mu_{x}\right)\right\} .
\end{aligned}
$$

where descriptions of the variables are provided in Section IV (see Table II). Note that the subscript $x$ is replaced with $r$ and $i$ to indicate the variables related to the rectifier and inverter, respectively. Moreover, $\beta$ corresponds to the firing and extinction angles (i.e., $\alpha$ and $\gamma$, respectively). As shown in Fig. 1, $\Delta \alpha$ and $\Delta \gamma$ can be estimated as:

$$
\Delta \beta= \pm H_{d c x 0}^{-1}\left(k_{p x}+k_{i x} / s\right)\left(\Delta H_{d c x}-\Delta H_{d c x_{-} r e f}\right),
$$

where $H$ corresponds to $V$ and $I$ for the voltage and current controllers, respectively: i.e., $(x, \beta, H)=(r, \alpha, V)$ or $(i, \gamma, I)$.

For the inverter, the linearized forms of (1), (2), and (4) correspond to (6)-(8), respectively:

$$
\begin{aligned}
\Delta V_{d c i} & =-a_{1 i} \sin \gamma_{0} \Delta \gamma-a_{2 i} \Delta I_{d c i}=-b_{1 i} \Delta \gamma-a_{2 i} \Delta I_{d c i}, \\
\Delta I_{d c i} & =\frac{1}{a_{3 i}}\left\{\sin \left(\gamma_{0}+\mu_{i 0}\right)-\sin \gamma_{0}\right\} \Delta \gamma+\frac{1}{a_{3 i}} \sin \left(\gamma_{0}+\mu_{i 0}\right) \Delta \mu_{i}, \\
& =\left(b_{2 i} \Delta \gamma+b_{3 i} \Delta \mu_{i}\right) / a_{3 i}, \\
\Delta P_{d c i} & =-2 a_{4 i} \sin \left(2 \gamma_{0}\right) \Delta \gamma+2 a_{4 i} \sin 2\left(\gamma_{0}+\mu_{i 0}\right)\left(\Delta \gamma+\Delta \mu_{i}\right), \\
& =b_{4 i} \Delta \gamma+b_{5 i} \Delta \mu_{i},
\end{aligned}
$$

where coefficients $a$ and $b$ are provided in the Appendix. By substituting (7) into (8), $\Delta P_{d c i}$ can also be expressed as:

$$
b_{3 i} \Delta P_{d c i}=a_{3 i} b_{5 i} \Delta I_{d c i}+\left(b_{3 i} b_{4 i}-b_{2 i} b_{5 i}\right) \Delta \gamma .
$$

Moreover, using (3) and (6), $\Delta P_{d c i}$ is given in another form as:

$$
\Delta P_{d c i} \approx I_{d c i 0} \Delta V_{d c i}+V_{d c i 0} \Delta I_{d c i}=\left(V_{d c i 0}-a_{2 i} I_{d c i 0}\right) \Delta I_{d c i}-b_{1 i} I_{d c i 0} \Delta \gamma
$$

Then, by integrating (9) and (10) into (5), the transient response $\Delta I_{d c i} / \Delta I_{d c i_{i} r e f}$ of the inverter can be represented as: 


$$
\left(a_{3 i} b_{5 i}-b_{3 i} c_{1 i}\right) \Delta I_{d c i}=a_{5 i} c_{2 i}\left(k_{p i}+\frac{k_{i i}}{s}\right)\left(\Delta I_{d c i-r e f}-\Delta I_{d c i}\right),
$$

which can be equivalently expressed as (12) (see below; the coefficients $c$ are also shown in the Appendix). For both real and benchmark HVDC systems, $\Delta I_{d c i} / \Delta I_{d c i}$ ref in (12) can be approximated to a strictly proper first-order transfer function, because the ratio of $m_{3}$ to $m_{1}$ has a magnitude comparable to that of $V_{d c r 0}$ to $I_{d c r 0}$ : e.g., $V_{d c r 0}=184,000 \mathrm{~V}, I_{d c r 0}=407.6 \mathrm{~A}$, and $m_{3} / m_{1}=7.7 \times 10^{-3}$ for a real 150-MW HVDC system [20].

Similarly, for the rectifier, the linearized forms of (1), (2), and (4) correspond to (13)-(15), respectively:

$$
\begin{aligned}
& \Delta V_{d c r}=-a_{1 r} \sin \alpha_{0} \Delta \alpha-a_{2 r} \Delta I_{d c r}=-b_{1 r} \Delta \alpha-a_{2 r} \Delta I_{d c r}, \\
& \begin{aligned}
\Delta I_{d c r} & =\frac{1}{a_{3 r}}\left\{\sin \left(\alpha_{0}+\mu_{r 0}\right)-\sin \alpha_{0}\right\} \Delta \alpha+\frac{1}{a_{3 r}} \sin \left(\alpha_{0}+\mu_{r 0}\right) \Delta \mu_{r}, \\
& =\left(b_{2 r} \Delta \alpha+b_{3 r} \Delta \mu_{r}\right) / a_{3 r}, \\
\Delta P_{d c r} & =-2 a_{4 r} \sin \left(2 \alpha_{0}\right) \Delta \alpha+2 a_{4 r} \sin 2\left(\alpha_{0}+\mu_{r 0}\right)\left(\Delta \alpha+\Delta \mu_{r}\right), \\
& =b_{4 r} \Delta \alpha+b_{5 r} \Delta \mu_{r} .
\end{aligned}
\end{aligned}
$$

By combining (13)-(15), $\Delta P_{d c r}$ is expressed as:

$$
a_{2 r} b_{3 r} \Delta P_{d c r}=-a_{3 r} b_{5 r} \Delta V_{d c r}+\left(a_{2 r} b_{3 r} b_{4 r}-a_{2 r} b_{2 r} b_{5 r}-a_{3 r} b_{1 r} b_{5 r}\right) \Delta \alpha
$$

Moreover, from (3) and (13), $\Delta P_{d c r}$ is given in another form as:

$$
\begin{aligned}
a_{2 r} \Delta P_{d c r} & \approx a_{2 r}\left(I_{d c r 0} \Delta V_{d c r}+V_{d c r 0} \Delta I_{d c r}\right), \\
& =\left(a_{2 r} I_{d c r 0}-V_{d c r 0}\right) \Delta V_{d c r}-b_{1 r} V_{d c r 0} \Delta \alpha .
\end{aligned}
$$

Integration of (5), (16) and (17) gives the transient response $\Delta V_{d c r} / \Delta V_{d c r_{-} r e f}$ of the rectifier:

$$
\frac{\Delta V_{d c r}}{\Delta V_{d c r_{-} r e f}}=\frac{a_{5 r} c_{1 r} k_{p r} s+a_{5 r} c_{1 r} k_{i r}}{\left(a_{5 r} c_{1 r} k_{p r}-c_{2 r}\right) s+a_{5 r} c_{1 r} k_{i r}}=\frac{n_{3} s+n_{2}}{n_{1} s+n_{2}},
$$

which can be further approximated to:

$$
\frac{\Delta V_{\text {der }}}{\Delta V_{\text {dcr_ref }}} \approx \frac{1}{\left(n_{1} / n_{2}\right) s+1} .
$$

This is because the ratio of $n_{3}$ to $n_{1}$ is determined mainly by $1 / V_{d c r}$; for example, $n_{3} / n_{1}$ is less than 0.01 for the real and benchmark HVDC systems [20], [21]. As shown in (12) and (19), the responsibilities to regulate $\Delta I_{d c i}$ and $\Delta V_{d c r}$ can be kept distinct and assigned to separate HVDC terminals.

In addition, given the symmetry of the dc-link model, the relationship between $\Delta V_{d c i}$ and $\Delta V_{d c r}$ can be represented as:

$$
\begin{aligned}
\Delta V_{d c i} & =\Delta V_{d c r}-(R+s L) \Delta I_{d c r}-(R+s L) \Delta I_{d c i}, \\
\text { and } \quad \Delta I_{d c r} & =\Delta I_{d c i}+s C \Delta V_{d c},
\end{aligned}
$$

where $\Delta V_{d c}=0.5 \cdot\left(\Delta V_{d c r}+\Delta V_{d c i}\right)$ is the voltage variation at the mid-point of the dc link. By substituting (21) into (20), $\Delta V_{d c i}$ can be equivalently represented as:

$$
\Delta V_{d c i}=\frac{1-0.5 s C(R+s L)}{1+0.5 s C(R+s L)} \Delta V_{d c r}-\frac{2(R+s L)}{1+0.5 s C(R+s L)} \Delta I_{d c i} .
$$

In practice, it is common that $L$ and $C$ (and, consequently, $L \cdot C$

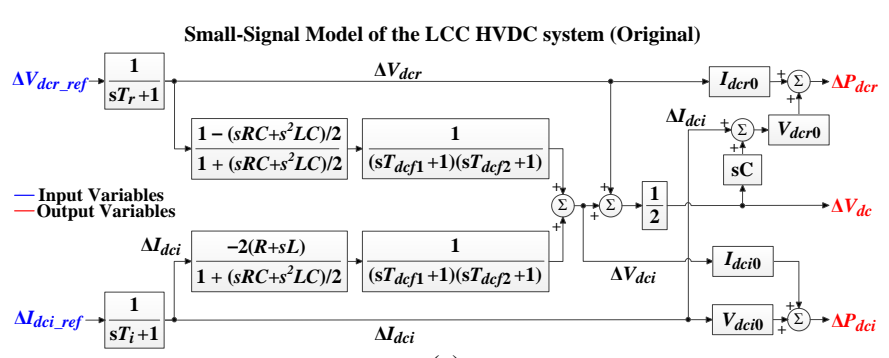

(a)

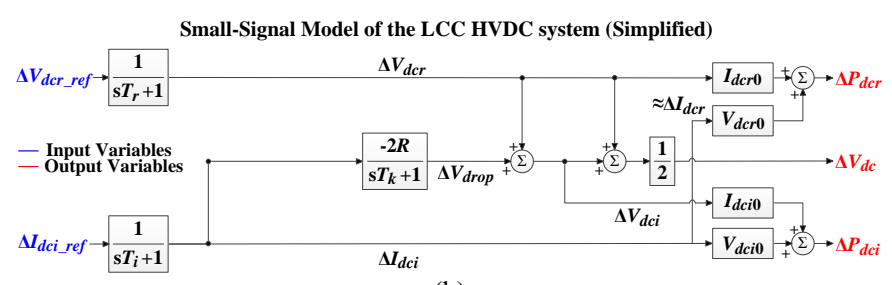

(b)

Fig. 2. (a) Original and (b) simplified small-signal models of the HVDC system considering the dynamics of the dc link, converters, and inner feedback loops.

and $R \cdot C$ ) are very small [22]-[24]. Under the common conditions of real HVDC systems, (22) can be simplified to:

$$
\begin{aligned}
\Delta V_{d c i} & =\frac{1 / s^{2}-0.5 R C / s-0.5 L C}{1 / s^{2}+0.5 R C / s+0.5 L C} \Delta V_{d c r}-\frac{2\left(R / s^{2}+L / s\right)}{1 / s^{2}+0.5 R C / s+0.5 L C} \Delta I_{d c i}, \\
& \approx \frac{1 / s^{2}-0.5 R C / s}{1 / s^{2}+0.5 R C / s} \Delta V_{d c r}-\frac{2\left(R / s^{2}+L / s\right)}{1 / s^{2}+0.5 R C / s} \Delta I_{d c i}, \\
& \approx \frac{1 / s^{2}}{1 / s^{2}} \Delta V_{d c r}-\frac{2 R / s^{2}}{1 / s^{2}+0.5 R C / s} \Delta I_{d c i}, \\
& =\Delta V_{d c r}-\frac{2 R}{s T_{k}+1} \Delta I_{d c i}, \quad \text { where } T_{k}=R C / 2 .
\end{aligned}
$$

In (23), the second term represents dynamic variation in the voltage drop along the dc link. Note that (23) still reflects the dc-link operation in the steady state (i.e., $V_{d c i}=V_{d c r}-2 R \cdot I_{d c i}$ ). Using (23), $\Delta P_{d c i}$ can be represented as:

$\Delta P_{d c i} \approx I_{d c i 0} \Delta V_{d c i}+V_{d c i 0} \Delta I_{d c i} \approx I_{d c i 0}\left(\Delta V_{d c r}-\frac{2 R}{s T_{k}+1} \Delta I_{d c i}\right)+V_{d c i 0} \Delta I_{d c i}$.

Furthermore, in practice, the variation in the capacitor charging current $\Delta I_{c}$ (i.e., $s C \Delta V_{d c}$ in (21)) is negligible compared to $\Delta I_{d c r}$ and $\Delta I_{d c i}$ given the small values of $C$ and $\Delta V_{d c}$. Therefore, (21) can be approximated to $\Delta I_{d c r} \approx \Delta I_{d c i}$, enabling $\Delta P_{d c r}$ to be expressed as:

$$
\Delta P_{d c r} \approx I_{d c r 0} \Delta V_{d c r}+V_{d c r 0} \Delta I_{d c r} \approx I_{d c r 0} \Delta V_{d c r}+V_{d c r 0} \Delta I_{d c i} .
$$

It can be seen in (24) and (25) that $\Delta P_{d c i}$ and $\Delta P_{d c r}$ differ only slightly under normal operating conditions (i.e., $V_{d c r 0}=V_{d c i 0}=1$ pu and $I_{d c r 0}=I_{d c i 0}=1 \mathrm{pu}$ ). Using the analysis above, the original and simplified small-signal models of the LCC HVDC system can be implemented as shown in Fig. 2(a) and (b), respectively. Note that the variation in ac voltage and reactive power at HVDC terminals is not considered due to marginal effects on the GFR. The profiles of $\Delta V_{d c r}, \Delta I_{d c i}$, and $\Delta P_{d c r(i)}$ obtained from (5)-(25) remain highly consistent with those acquired from the

$$
\frac{\Delta I_{d c i}}{\Delta I_{d c i \_r e f}}=\frac{k_{p i} a_{5 i} c_{2 i} \cdot s+k_{i i} a_{5 i} c_{2 i}}{\left\{a_{3 i} b_{5 i}-b_{3 i} c_{1 i}+k_{p i} a_{5 i} c_{2 i}\right\} \cdot s+k_{i i} a_{5 i} c_{2 i}}=\frac{m_{3} s+m_{4}}{m_{1} s+m_{2}}=\frac{m_{3}}{m_{1}}+\frac{m_{4}-\left(m_{2} m_{3} / m_{1}\right)}{m_{1} s+m_{2}} \approx \frac{1}{\left(m_{1} / m_{2}\right) s+1}
$$


comprehensive MATLAB/ SiMULINK model (see Section IV-B).

In general, dc filters are installed at HVDC terminals to mitigate dc-side harmonic currents and voltages [25]. In the original small-signal model, the operations of dc filters were represented using second-order transfer functions [26], as shown in Fig. 2(a). For brevity, the simplified model is implemented without the dc filters because, in (23), the relationships of $\Delta V_{d c i}$ with $\Delta V_{d c r}$ and $\Delta I_{d c i}$ have already been represented using the zero- and first-order characteristic equations (i.e., $\Delta_{V}(s)=1$ and $\Delta_{I}(s)=s T_{k}+1$, respectively). This does not compromise the consistency of the original and simplified small-signal models, as discussed in Section IV-B. In other words, the proposed strategy is not conditional on the nature of the dc harmonic filters.

\section{B. Real-time GFR Support Provided by LCC HVDC System}

Fig. 3 shows a block diagram of the proposed control strategy, where the LCC HVDC system supports the GFR on the rectifier- and inverter-side grids. It includes the dynamic model of the HVDC system developed in Section II-A. The GFR support afforded by the proposed strategy is effective under the common operating conditions of the sending-end grid, where the total power generation (i.e., the sum of $P_{g r}$ and $\left.P_{w}\right)$ is greater than the total load demand $P_{l r}$. Consequently, the HVDC system transfers the surplus power $P_{d c r}$ to the receiving-end grid. Apart from these general conditions, no restriction or requirement is imposed on the WF. Therefore, for simplicity, the WF has been modeled as an intermittent power source [27]. Similarly, the accumulated dynamic response of the generators on each-side grid is represented by a second-order transfer function [28].

The reference signals of the HVDC system consist of two components, corresponding to PFC and SFC, as in the case of a common GFR scheme for generators. The PFC is achieved using droop controllers with coefficients of $R_{i(r)}$ and $K_{i(r)}$. Active power sharing between the HVDC converters and generators is achieved using controllers with $R_{i(r)}$, so that $\Delta f_{i(r)}$ can be stabilized in a localized manner. Similarly, using controllers with $K_{i(r)}, \Delta V_{d c}$ is stabilized via dc power sharing between the HVDC converters. The inertial responses are also emulated using derivative controllers to further exploit the fast dynamics of the HVDC converters.

The PFC support of an HVDC converter acts as a disturbance in the ac grid interfaced with the other converter. For example, $f_{i}$ decreases for an increase in $P_{l i}$, activating the droop controller with $R_{i}$. This increases $P_{d c i}$ and, consequently, $P_{d c r}$ (see (24) and (25)), leading to a decrease in $f_{r}$. Furthermore, the frequency deviation leads to conflict between the droop controllers. Specifically, for $\Delta f_{r}<0$, the controller with $R_{r}$ is then activated to reduce $P_{d c r}$ and hence $P_{d c i}$, whereas the controller with $R_{i}$ would still attempt to increase $P_{d c i}$ to stabilize $f_{i}$. Moreover, as the reduction in $P_{d c r}$ is achieved by decreasing $V_{d c r_{-} r e f}$, the controllers with $K_{r}$ and $K_{i}$ are activated to increase $P_{d c r}$ and decrease $P_{d c i}$, respectively. In other words, dc power sharing degrades the PFC support of the controllers with $R_{r}$ and $R_{i}$. Similarly, $\Delta f_{i}$ resulting from $\Delta P_{l r}$ causes conflicts in the operations of the localized, droop controllers. Given the droop control characteristics, an LQG controller is designed for the coordinated SFC of $\Delta V_{d c r}$ and $\Delta I_{d c i}$ for the HVDC system and $\Delta P_{g r}$ and $\Delta P_{g i}$ for the generators, as discussed in Section III, restoring $f_{i}, f_{r}$, and $V_{d c}$ to their nominal values.

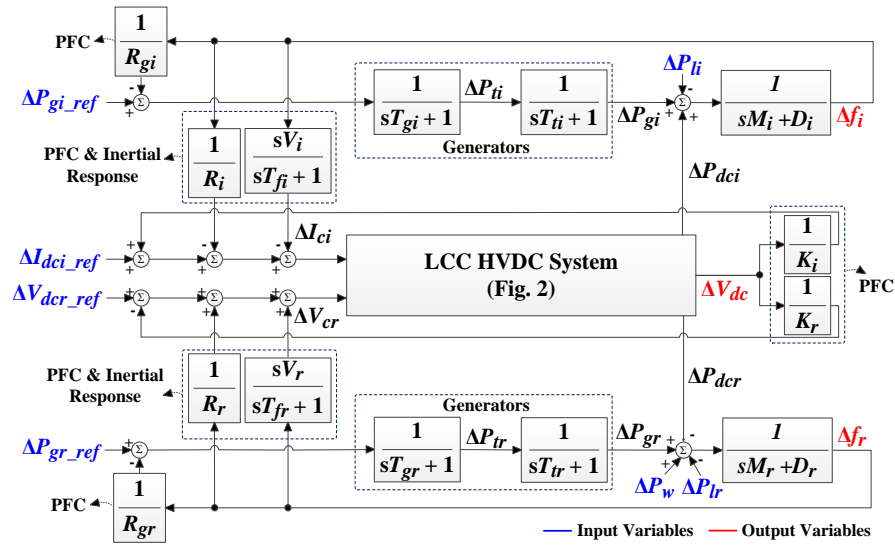

Fig. 3. Proposed GFR support by the HVDC system via inertia emulation, PFC, and SFC with variation in the load demands and WF power generation.

\section{DESIGN AND ANALYSIS OF AN LQG CONTROLLER FoR OPTIMAL SFC OF LCC HVDC SYSTEM}

\section{A. Design of an LQG Controller for Optimal SFC}

The small-signal model of the HVDC system and generators, shown in Fig. 3, can be represented in state space form as:

$$
\begin{aligned}
& d \mathbf{X}(t) / d t=\mathbf{A} \cdot \mathbf{X}(t)+\mathbf{B}_{\mathbf{r}} \cdot \mathbf{r}(t)+\mathbf{B}_{\mathbf{w}} \cdot \mathbf{w}(t), \\
& \mathbf{Y}(t)=\mathbf{C} \cdot \mathbf{X}(t),
\end{aligned}
$$

with the states, inputs, and outputs arranged, respectively, as:

$$
\begin{aligned}
\mathbf{X}(t)= & {\left[\Delta f_{i}, \Delta P_{g i}, \Delta P_{t i}, \Delta I_{c i}, \Delta I_{d c i},\right.} \\
\left.\Delta f_{r}, \Delta P_{g r}, \Delta P_{t r}, \Delta V_{c r}, \Delta V_{d c r}, \Delta V_{d r o p}\right]^{T}, & \\
\mathbf{r}(t)= & {\left[\Delta P_{g i_{-} r e f}, \Delta P_{g r_{-} r e f}, \Delta I_{d c i_{-} r e f}, \Delta V_{d c r_{-} r e f}\right]^{T}, } \\
\mathbf{w}(t)= & {\left[\Delta P_{l i}, \Delta P_{l r}-\Delta P_{w}\right]^{T}, } \\
\mathbf{Y}(t)= & {\left[\Delta f_{i}, \Delta f_{r}, \Delta V_{d c r}, \Delta V_{d r o p}\right]^{T}, }
\end{aligned}
$$

where $\mathbf{A}, \mathbf{B}_{\mathbf{r}}, \mathbf{B}_{\mathbf{w}}$, and $\mathbf{C}$ are presented in the Appendix. In (28), $\Delta V_{d r o p}$ is defined as $\Delta V_{d c i}-\Delta V_{d c r}$.

For optimal SFC, (26) and (27) are augmented by integrating the integrals of $\left[\Delta f_{i}, \Delta f_{r}, \Delta V_{d c r}, \Delta V_{d r o p}\right]^{T}$ with $\mathbf{X}(t)$ and $\mathbf{Y}(t)$ as:

$$
\begin{aligned}
& \frac{d}{d t}\left[\int \Delta f_{i} d t \quad \int \Delta f_{r} d t \quad \int \Delta V_{d c r} d t \quad \int \Delta V_{d r o p} d t \quad \mathbf{X}(t)\right]^{T}= \\
& {\left[\begin{array}{c:ccc} 
& 1 & {[\mathbf{O}]_{1 \times 5}} & {[\mathbf{O}]_{1 \times 5}} \\
{[\mathbf{O}]_{4 \times 4}} & {[\mathbf{O}]_{1 \times 5}} & 1 & {[\mathbf{O}]_{1 \times 5}} \\
& {[\mathbf{O}]_{1 \times 9}} & 1 & 0 \\
{[\mathbf{O}]_{1 \times 5}} & {[\mathbf{O}]_{1 \times 5}} & 1 \\
\hdashline \mathbf{O}]_{1 \times 4} & & \mathbf{A} &
\end{array}\right]\left[\begin{array}{c}
\int \Delta f_{i} d t \\
\int \Delta f_{r} d t \\
\int \Delta V_{d c r} d t \\
\int \Delta V_{d r o p} d t \\
\mathbf{X}(t)
\end{array}\right]+\left[\begin{array}{c}
\mathbf{O} \\
\mathbf{B}
\end{array}\right] \mathbf{r}(t)+\left[\begin{array}{c}
\mathbf{O} \\
\mathbf{B}_{\mathbf{w}}
\end{array}\right] \mathbf{w}(t)} \\
& {\left[\mathbf{Y}(t), \int \Delta f_{i} d t, \int \Delta f_{r} d t, \int \Delta V_{d c r} d t, \int \Delta V_{d r o p} d t\right]^{T}=} \\
& {\left[\begin{array}{lc}
{[\mathbf{O}]_{4 \times 4}} & \mathbf{C} \\
{[\mathbf{I}]_{4 \times 4}} & {[\mathbf{O}]_{4 \times 11}}
\end{array}\right] \cdot\left[\int \Delta f_{i} d t \int \Delta f_{r} d t \int \Delta V_{d c r} d t \int \Delta V_{d r o p} d t \quad \mathbf{X}(t)\right]^{T} \text {. }}
\end{aligned}
$$




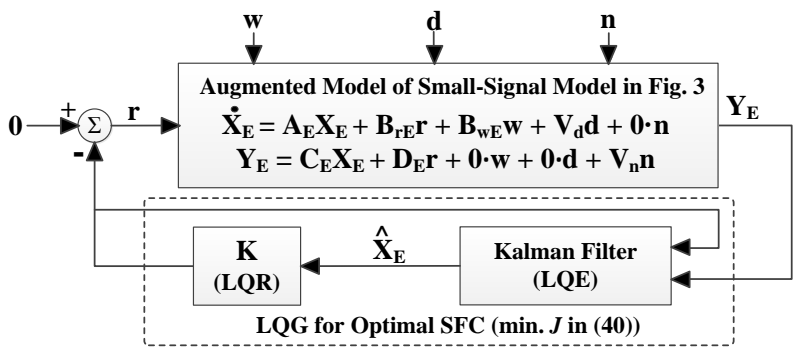

Fig. 4. An LQG controller integrated with the small-signal model (see Fig. 3) of the LCC HVDC system and conventional generators.

The augmented state-space model given by (32) and (33) can be represented in compact form as:

$$
\begin{aligned}
& \frac{d}{d t} \mathbf{X}_{\mathbf{E}}(t)=\mathbf{A}_{\mathbf{E}} \cdot \mathbf{X}_{\mathbf{E}}(t)+\mathbf{B}_{\mathrm{rE}} \cdot \mathbf{r}(t)+\mathbf{B}_{\mathbf{w E}} \cdot \mathbf{w}(t), \\
& \mathbf{Y}_{\mathbf{E}}(t)=\mathbf{C}_{\mathbf{E}} \cdot \mathbf{X}_{\mathbf{E}}(t),
\end{aligned}
$$

where

$$
\begin{aligned}
& \mathbf{X}_{\mathbf{E}}(t)=\left[\int \Delta f_{i} d t, \int \Delta f_{r} d t, \int \Delta V_{d c r} d t, \int \Delta V_{d r o p} d t, \mathbf{X}(t)\right]^{T}, \\
& \mathbf{Y}_{\mathbf{E}}(t)=\left[\mathbf{Y}(t), \int \Delta f_{i} d t, \int \Delta f_{r} d t, \int \Delta V_{d c r} d t, \int \Delta V_{d r o p} d t\right]^{T} .
\end{aligned}
$$

The augmented coefficient matrices are given as:

$\mathbf{A}_{\mathbf{E}}=\left[\begin{array}{ll}\mathbf{O} & \mathbf{A}_{\mathrm{s}} \\ \mathbf{O} & \mathbf{A}\end{array}\right], \mathbf{B}_{\mathrm{rE}}=\left[\begin{array}{c}\mathbf{O} \\ \mathbf{B}_{\mathbf{r}}\end{array}\right], \mathbf{B}_{\mathrm{wE}}=\left[\begin{array}{c}\mathbf{O} \\ \mathbf{B}_{\mathrm{w}}\end{array}\right], \mathbf{C}_{\mathbf{E}}=\left[\begin{array}{cc}\mathbf{O} & \mathbf{C} \\ \mathbf{I} & \mathbf{O}\end{array}\right]$

where

$$
\mathbf{A}_{\mathbf{s}}=\left[\begin{array}{ccc}
1 & {[\mathbf{O}]_{1 \times 5}} & {[\mathbf{O}]_{1 \times 5}} \\
{[\mathbf{O}]_{1 \times 5}} & 1 & {[\mathbf{O}]_{1 \times 5}} \\
{[\mathbf{O}]_{1 \times 9}} & 1 & 0 \\
{[\mathbf{O}]_{1 \times 5}} & {[\mathbf{O}]_{1 \times 5}} & 1
\end{array}\right] .
$$

Moreover, communication time delays and measurement noise are reflected in the augmented model, as shown in Fig. 4; these are modeled as input and output disturbances $\mathbf{d}(t)$ and $\mathbf{n}(t)$, respectively, using normally distributed random variables.

As shown in Fig. 4, a state feedback controller $\mathbf{r}(t)=-\mathbf{K} \cdot \mathbf{X}_{\mathbf{E}}(t)$ is integrated with the augmented model to minimize the maximum variations in $f_{i}, f_{r}$, and $V_{d c}$, while also restoring them to the nominal values in steady state. Considering the control efforts of the HVDC system and generators, a cost function for the feedback controller can be formulated as:

$$
J=\int_{0}^{\infty}\left(\mathbf{X}_{\mathbf{E}}(t)^{T} \cdot \mathbf{Q} \cdot \mathbf{X}_{\mathbf{E}}(t)+\mathbf{r}(t)^{T} \cdot \mathbf{R} \cdot \mathbf{r}(t)\right) d t .
$$

In (40), $\mathbf{Q}$ is a diagonal matrix with weighting coefficients, each of which is multiplied by the square of each state variable $\int \Delta f_{i} d t, \int \Delta f_{r} d t, \int \Delta V_{d c r} d t, \int \Delta V_{d r o p} d t, \Delta f_{i}, \Delta f_{r}, \Delta V_{d c r}$, and $\Delta V_{d r o p}$, in $\mathbf{X}_{\mathbf{E}}(t)$. Similarly, $\mathbf{R}$ is a diagonal matrix with weighting coefficients for the squares of the input variables in $\mathbf{r}(t)$. Each coefficient in $\mathbf{Q}$ and $\mathbf{R}$ can be determined adaptively by considering the operating conditions of the HVDC system and interfacing grids. For example, by increasing the coefficients of terms related to $\Delta V_{d c r}$, we can prevent excessive variation in the dc-link voltage and firing angle, while still improving the real-time GFR, as discussed in Section IV-E. For $\mathbf{Q}$ and $\mathbf{R}$, there is a matrix of $\mathbf{K}=\mathbf{R}^{-1} \cdot \mathbf{B r}^{T} \cdot \mathbf{P}$ minimizing $J$ in (40), such that $\mathbf{P}$ is the solution to:

$$
\mathbf{A E}_{\mathbf{E}}^{T} \cdot \mathbf{P}+\mathbf{P} \cdot \mathbf{A}_{\mathbf{E}}+\mathbf{Q}-\mathbf{P} \cdot \mathbf{B} \cdot \mathbf{R}^{-1} \cdot \mathbf{B}^{T} \cdot \mathbf{P}=\mathbf{O} .
$$

To establish the optimal $\mathbf{r}(t)$, all states in $\mathbf{X}_{\mathbf{E}}(t)$ need to be measurable. As shown in Fig. 4, a Kalman filter [29] is often adopted to estimate the unknown states, using the measured states or outputs $\mathbf{Y}_{\mathbf{E}}(t)$ : i.e.,

$$
\mathbf{r}(t)=-\mathbf{K} \cdot \mathbf{X}_{\mathbf{E}}(t) \approx-\mathbf{K} \cdot \hat{\mathbf{X}}_{\mathbf{E}}(t),
$$

where $\widehat{\mathbf{X}}_{\mathbf{E}}$ is the estimate of $\mathbf{X}_{\mathbf{E}}$. Given the successful performance of the Kalman filter (i.e., $\widehat{\mathbf{X}}_{\mathbf{E}} \approx \mathbf{X}_{\mathrm{E}}$ ), the transfer function matrix $\mathbf{V}(s)$ between $\mathbf{w}(s)$ and $\mathbf{Y}_{\mathbf{E}}(s)$ of the complete state-space model, shown in Fig. 4, is obtained as:

$$
\mathbf{Y}_{\mathbf{E}}(s)=\mathbf{V}(s) \cdot \mathbf{w}(s)=\mathbf{C}_{\mathbf{E}}\left[s \mathbf{I}-\left(\mathbf{A}_{\mathbf{E}}-\mathbf{B}_{\mathrm{rE}} \mathbf{K}\right)\right]^{-1} \mathbf{B}_{\mathbf{w E}} \cdot \mathbf{w}(s),
$$

or, equivalently,

$$
\left[\begin{array}{c}
\Delta f_{i}(s) \\
\Delta f_{r}(s) \\
\vdots
\end{array}\right]=\left[\begin{array}{cc}
V_{11}(s) & V_{12}(s) \\
V_{21}(s) & V_{22}(s) \\
\vdots & \vdots
\end{array}\right]\left[\begin{array}{c}
\Delta P_{l i}(s) \\
\Delta P_{l r}(s)-\Delta P_{w}(s)
\end{array}\right] .
$$

B. Eigenvalue Analysis of the Proposed GFR Support

Eigenvalues of $V 11(s)=\Delta f_{i}(s) / \Delta P_{l i}(\mathrm{~s})(\mathrm{Jeju}-H a e n a m$ \& CIGRE)

(a)

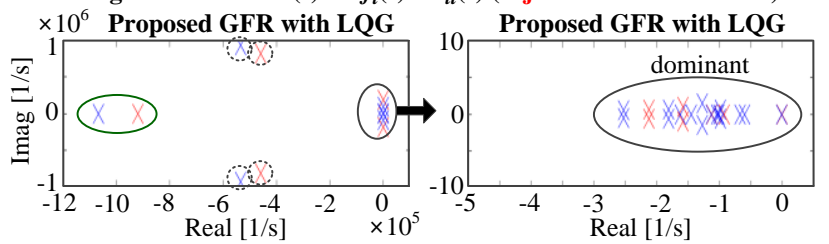

(b)

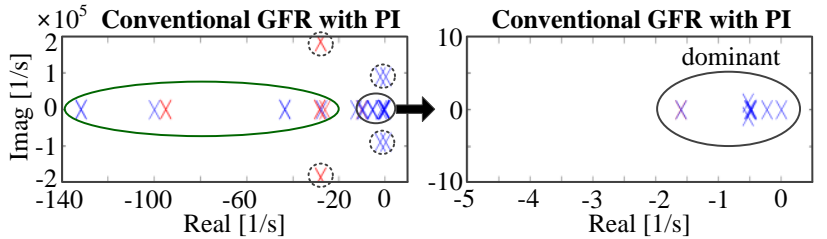

Fig. 5. Eigenvalues of $\Delta f_{i} / \Delta P_{l i}$ : (a) proposed and (b) conventional GFR.

Root Loci of $V 11(\mathrm{~s})=\Delta f_{i}(\mathrm{~s}) / \Delta P_{l i}(\mathrm{~s})$ (Proposed, Jeju-Haenam \& CIGRE)
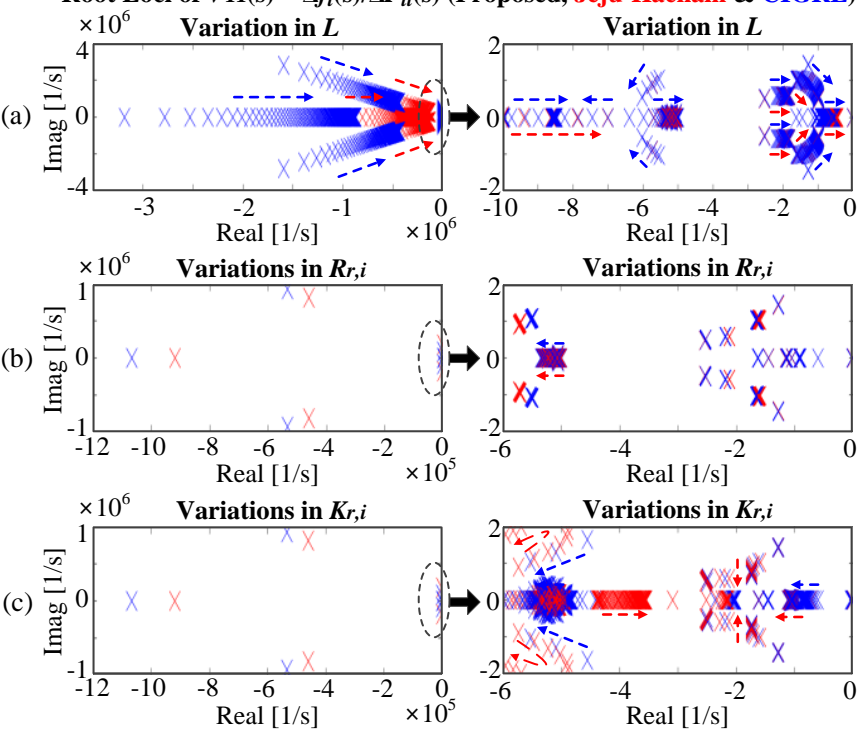

Fig. 6. Root loci of $\Delta f_{i} / \Delta P_{l i}$ in the proposed strategy for increasing (a) $L$ from $4.4 \times 10^{-5}$ pu to $4.4 \times 10^{-3}$ pu and (b) $R_{i(r)}$ and (c) $K_{i(r)}$ from 0.1 to 10.0 .

Using (44), eigenvalue analysis is performed for two types of LCC HVDC system (i.e., the Jeju-Haenam system [20] and the CIGRE benchmark system [21]), focusing on the frequency deviations for the load demand variations: i.e., $\Delta P_{w}(s)=0$. Fig. 5 shows the eigenvalues of $\Delta f_{i}(s) / \Delta P_{l i}(s)$ for the proposed and conventional GFR strategies, where the LQG and PI controllers, 
respectively, are adopted for the SFC of the HVDC system and generators. For both strategies, the eigenvalues are the same as those of $\Delta f_{i}(s) / \Delta P_{l r}(s), \Delta f_{r}(s) / \Delta P_{l r}(s)$, and $\Delta f_{r}(s) / \Delta P_{l i}(s)$.

Specifically, Fig. 5(a) shows that, with the proposed strategy, both types of HVDC system have three groups of poles: i.e., (Group A) the poles located far from the imaginary axis; (Group B) the complex conjugate poles with large imaginary values; and (Group C) the poles placed close to the imaginary axis. In Groups A to $\mathrm{C}$, the poles are encircled by the green line, black dotted lines, and black line, respectively. In this paper, Group C has been defined as the dominant poles; the most dominant pole is not specified, because all poles of Group C significantly affect the dynamic responses of the HVDC system and the interfacing grids. Similarly, Fig. 5(b) shows that, with the conventional strategy, the dominant poles lie in the $s$-plane with the real and imaginary axes ranging from -5 to 0 and from -10 to 10 , respectively, as in the proposed strategy. This allows for a fair comparison between the proposed and conventional strategies. For both HVDC systems, the dominant poles and complex-conjugate poles with large imaginary values are located further away from the imaginary axis with the proposed strategy than with the conventional strategy. This indicates that, in the proposed strategy, $f_{i}$ can be restored to the nominal value with a faster response time and smaller oscillations.

In addition, Fig. 6 shows the root loci of $\Delta f_{i}(s) / \Delta P_{l i}(s)$ in the proposed GFR strategy when the dc-link parameters and controller gains of the HVDC system vary. Root locus analysis explores the performance of the proposed strategy applied to various HVDC units differing in terms of both parameters and gains, confirming that the strategy is widely applicable. Note that the root locus consists of the poles obtained using different optimal values of $\mathbf{K}$ for each set of $\left(L, R, C, R_{i}, R_{r}, K_{i}, K_{r}\right)$. Specifically, the dc-link parameters $L, R$, and $C$ increase from $4.4 \times 10^{-5}$ to $4.4 \times 10^{-3} \mathrm{pu}$, from $4.4 \times 10^{-4}$ to $4.4 \times 10^{-2} \mathrm{pu}$, and from $1.1 \times 10^{-8}$ to $8.8 \times 10^{-7} \mathrm{pu}$, respectively [30], [31]; the ranges have been determined based on the dc-link parameters of common HVDC systems [31]-[33]. Moreover, the droop coefficients, $R_{i(r)}$ and $K_{i(r)}$, increase from 0.1 to 10.0 . The wider the ranges of the parameters, the more thorough and complete the analysis.

In Fig. 6(a), as $L$ increases, the poles move towards the imaginary axis in both types of HVDC system, thus decreasing the damping ratio and increasing the settling time of the closed-loop system (i.e., Fig. 4). Then, $\Delta f_{i}$ caused by $\Delta P_{l i}$ becomes more persistent, returning to zero after longer time delays. In other words, the HVDC system responds more slowly to reference signals delivered by the grid- and converter-level controllers, thus contributing little to real-time GFR in interfacing grids. Therefore, for real-time GFR support, dc link and dc harmonic filters with low inductance are preferred to move the real and complex-conjugate poles away from the imaginary axis. Note that if the inductance is too low, the dc filters are not effective and the HVDC system becomes highly sensitive to internal and external disturbances. On the other hand, if the inductance is too high, the HVDC system operation is likely to become unstable with large oscillations in the transferred power. For brevity, the root loci of the variations in $R$ and $C$ are not provided, because the variations only marginally affect the eigenvalues. Fig. 6(b) and (c) also show that, as $R_{i(r)}$ and $K_{i(r)}$ increase, the dominant poles on the real axis move away from the imaginary axis for both types of system. This indicates that the droop controllers of the HVDC converters, discussed in Section II-B, are well coordinated, stabilizing the frequency successfully within a short period after the load disturbance.

\section{CASE STUdies AND Results}

A. Test System and Simulation Conditions

TABLE II. PARAMETERS FOR THE CASE STUdIES

\begin{tabular}{|c|c|c|c|c|}
\hline Devices & \multicolumn{2}{|l|}{ Description } & Parameters & Values \\
\hline $\begin{array}{c}\text { Jeju-Haenam } \\
\text { HVDC } \\
\text { system }\end{array}$ & $\begin{array}{l}\text { Nominal de } \\
\text { Nominal dc c } \\
\text { HVDC-link } \\
\text { Converter rec } \\
\text { Converter ov } \\
\text { Firing and ex } \\
\text { TR secondar } \\
\text { TR tap ratios } \\
\text { Voltage contr } \\
\text { Current contr } \\
\text { Number of b } \\
\text { Time constan } \\
\text { converters an } \\
\text { Time constan }\end{array}$ & $\begin{array}{l}\text { ages } \\
\text { rents } \\
\text { ameters } \\
\text { ance } \\
\text { ap angles } \\
\text { ction angles } \\
\text { oltages } \\
\text { er gains } \\
\text { er gains } \\
\text { ges } \\
\text { of HVDC } \\
\text { he dc link } \\
\text { of dc filters }\end{array}$ & \begin{tabular}{l|}
$V_{d c r 0}, V_{d c i 0}[\mathrm{kV}]$ \\
$I_{d c r 0}, I_{d c i 0}[\mathrm{~A}]$ \\
$R[\Omega], L[\mathrm{H}], C[\mu \mathrm{F}]$ \\
$X_{c r}, X_{c i}[\Omega]$ \\
$\mu_{r 0}, \mu_{i 0}\left[^{\circ}\right]$ \\
$\alpha_{0}, \gamma_{0}\left[^{\circ}\right]$ \\
$V_{l r}, V_{l i}[\mathrm{kV}]$ \\
$T R_{r}, T R_{i}$ \\
$k_{p r}, k_{i r}$ \\
$k_{p i}, k_{i i}$ \\
$N$ \\
$T_{r(i)}, T_{k}, T_{f r(i)}$ \\
$T_{d c f 1}, T_{d c f 2}$ \\
\end{tabular} & $\begin{array}{l}184.0,183.5 \\
407.6 \\
1.116,0.2,54 \\
7.99 \\
2.44 \\
15.0,18.0 \\
75.9,82.2 \\
0.9 \\
5.5,20.1 \\
0.001,10.0 \\
2 \\
0.02,0.001,0.1 \\
0.01,0.08\end{array}$ \\
\hline $\begin{array}{l}\text { Generators } \\
\text { in ac grids }\end{array}$ & \multicolumn{2}{|c|}{$\begin{array}{l}\text { Inertia and damping } \\
\text { Time constants }\end{array}$} & $\begin{array}{l}M_{r}, M_{i}, D_{i}, D_{r} \\
T_{g r}, T_{g i}, T_{t r}, T_{t i}\end{array}$ & $\begin{array}{l}5,5,1,1 \\
0.2,0.2,0.5,0.5\end{array}$ \\
\hline $\mathrm{PFC}$ & $\begin{array}{l}\text { Emulated ine } \\
\text { Droop gains } \\
\text { Droop gains }\end{array}$ & VDC) & $\begin{array}{l}V_{r}, V_{i} \\
K_{r}, K_{i}, R_{r}, R_{i} \\
R_{g r}, R_{g i}\end{array}$ & $\begin{array}{l}5 \\
0.5 \\
0.5 \\
\end{array}$ \\
\hline $\begin{array}{c}\text { SFC } \\
\text { (Conv.) }\end{array}$ & \multicolumn{2}{|c|}{$\begin{array}{l}\text { PI gains (HVDC) } \\
\text { PI gains (Gen.) }\end{array}$} & $\begin{array}{l}K P_{r}, K P_{i}, K I_{r}, K I_{i} \\
K P_{r}, K P_{i}, K I_{r}, K I_{i}\end{array}$ & $\begin{array}{l}9,9,6,6 \\
9,9,6,6\end{array}$ \\
\hline \multicolumn{5}{|c|}{ TABLE III. FEATURES OF THE PROPOSED AND CONVENTIONAL STRATEGIES } \\
\hline Proposed & $\begin{array}{l}\text { Case } 1 \\
\text { Case } 2 \\
\text { Case } 3\end{array}$ & $\begin{array}{l}\text { time-varying } \\
\text { time-varying } \\
\text { fixed }\end{array}$ & $\begin{array}{l}\text { both-side gri } \\
\text { both-side gri } \\
\text { inverter-side }\end{array}$ & $\begin{array}{l}\text { LQG } \\
\text { PI } \\
\text { PI }\end{array}$ \\
\hline
\end{tabular}

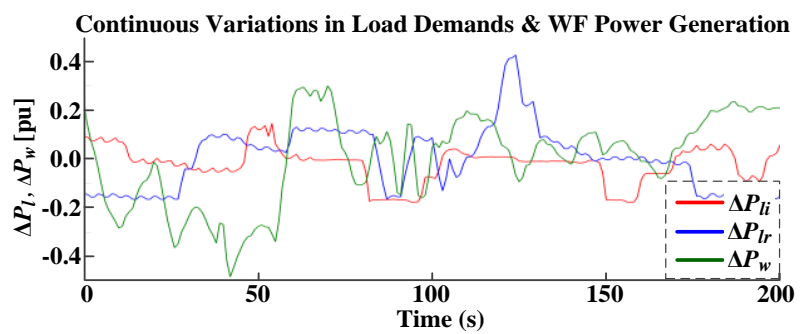

Fig. 7. Continuous variations in load demands and wind power generation.

The proposed optimal control strategy was tested using the parameter sets and operating conditions of two HVDC systems: the Jeju-Haenam system [20], [34] and the CIGRE benchmark system [21]. The Jeju-Haenam system has a rated power of 150 MW and a rated voltage of $184 \mathrm{kV}$. It delivers surplus power generated at the rectifier terminal of the Haenam grid to the inverter terminal of the Jeju grid via a $100-\mathrm{km}$ dc cable. The Jeju grid is weaker than the Haenam grid; the short-circuit ratios of the Jeju and Haenam grids are 4.0 and 14.4, respectively [35], [36]. The HVDC converters operate with both constant and time-varying power references under normal conditions. Each converter includes a converter transformer, 12 thyristor valves, and internal controllers that regulate the firing or extinction angles. Table II lists the real parameters of the Jeju-Haenam system [17], [37] and the model parameters of the non-reheat turbine generators [28] in the rectifier- and 
inverter-side grids. It also shows the coefficients for the emulated inertial responses and droop controllers, as well as the PI controllers for the conventional strategy. The real and benchmark HVDC systems were comprehensively modeled in MATLAB/SIMULINK using averaged circuit models of the converters, detailed models of the dc link and converter transformers, and grid- and converter-level controllers with nonlinear signal processing capabilities. The comprehensive model was used to validate the small-signal model and hence the proposed strategy.

Table III shows the main features of the proposed (Case 1) and conventional (Cases 2 and 3) strategies. The comparison between Cases 1 and 2 was taken into account to analyze the effect of the proposed LQG controller on the real-time GFR, given the operating characteristics of the droop controllers, discussed in Sections II-B and III-A. Moreover, Case 3 represents a common condition of the HVDC system [6], [8] to support only the inverter-side GFR: i.e., no feedback loops with $1 / R_{r}, s \cdot V_{r}, K_{r}$, and $K_{i}$. We compared Case 1 and Case 3 to analyze the effectiveness of the proposed dc voltage control for improving the GFR on both rectifier and inverter sides. Note that in Cases 1-3, the control input of $I_{d c i}$ ref is integrated with the feedback loops for the inertia emulation, PFC, and SFC. This allows for a fair comparison between the proposed and conventional strategies in terms of the optimal time-varying control of $V_{d c r}$, which is the main focus of this paper. Due to the inertia emulation, the fast response of the inverter can be successfully exploited in Cases $1-3$, increasing or decreasing $I_{d c i}$ almost instantaneously after load disturbance. Fig. 7 shows the variations in load demands $\Delta P_{l i}$ and $\Delta P_{l r}$, reflecting the scaled-up RegD signals [38] over a time period of $200 \mathrm{~s}$. It also shows the intermittent power generation $\Delta P_{w}$ of the WF. In addition to these profiles, stepwise variations in $\Delta P_{l i}$ and $\Delta P_{l r}$ were considered to evaluate the performance of the GFR support provided by the HVDC system.

B. Validating the Small-Signal Model of the HVDC System
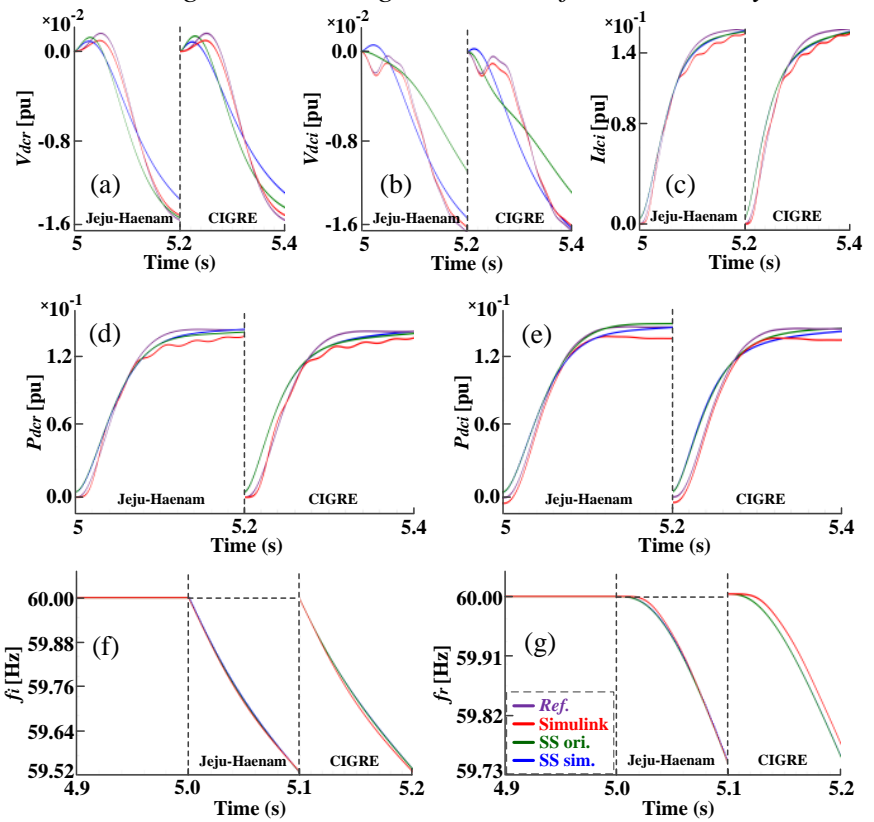

Fig. 8. Close-up plots of the step responses to $\Delta P_{l i}(t)=0.3$ pu for the proposed strategy: (a) $V_{d c r}$, (b) $V_{d c i}$, (c) $I_{d c i}$, (d) $P_{d c r}$, (e) $P_{d c i}$, (f) $f_{i}$, and (g) $f_{r}$.
We compared the transient responses of the small-signal models and the comprehensive SIMULINK model, discussed in Sections II-A and IV-A, respectively, for both types of HVDC system to a step variation in $P_{l i}$ of 0.3 pu. Fig. 8(a)-(c) show that, for both types, the transient responses of the three models were similar to each other for each profile of $V_{d c}, V_{d c}$, and $I_{d c i}$, respectively. This also led to good consistency between the simplified small-signal model and the other models for each profile of $P_{d c r}$ and $P_{d c i}$ and, consequently, of $f_{r}$, and $f_{i}$, as shown in Fig. 8(d)-(g), respectively. The simplified model reflected well the HVDC system operation when $L \leq 5 \mathrm{H}$ and $C \leq 500 \mu \mathrm{F}$. In general, the $L$ and $C$ of real HVDC systems are considerably smaller than $5 \mathrm{H}$ and $500 \mu \mathrm{F}$, respectively [31]-[33]. This implies that conversion from the original small-signal model to the simplified model is valid under common practical operating conditions of HVDC systems, confirming the accuracy of the case study results obtained using the simplified model presented in Sections IV-C, D, and E.

\section{Comparisons of Stepwise Load Demand Variations}

Fig. 9 shows $f_{i}, f_{r}, V_{d c}$, and $I_{d c}$ for the step responses of the Jeju-Haenam HVDC system to $\Delta P_{l i}$ and $\Delta P_{l r}$, which increased by $0.3 \mathrm{pu}$ at $t=5 \mathrm{~s}$ and $35 \mathrm{~s}$, respectively, over $15 \mathrm{~s}$. As indicated in Table IV, the proposed strategy (i.e., Case 1) decreased the sum of the maximum deviations of $f_{i}$ and $f_{r}$ (i.e., $\left.\left|\Delta f_{i}\right|_{\max }+\left|\Delta f_{r}\right|_{\max }\right)$ by $28.8 \%$ and $21.8 \%$, compared to the conventional strategies (i.e., Cases 2 and 3, respectively), while resulting in a maximum variation in the dc-link voltage of only 4.3\%. Moreover, in Case $1, f_{i}$ and $f_{r}$ were restored back to the nominal value more rapidly, and with smaller overshooting than in Cases 2 and 3.

Fig. 10 shows the variations in $\alpha$ and $\gamma$ for the optimal profiles of $V_{d c}$ and $I_{d c}$. In Case 1, the decreases in $f_{i}$ and $f_{r}$ at $t=5$ $\mathrm{s}$ activated the inertia emulation (with gains of $V_{i}$ and $V_{r}$ ) and the frequency-power droop control (with gains of $R_{i}$ and $R_{r}$ ) of the HVDC converters. This decreased $V_{d c r_{-} \text {ref }}$ and increased $I_{d c i}$ ref, triggering rapid increases in both $\alpha$ and $\gamma$ at $t=5 \mathrm{~s}$. The reduction in $V_{d c r_{-} r e f}$ (and hence $V_{d c}$ ) activated the dc voltagepower droop control (with gains of $K_{i}$ and $K_{r}$ ), thus increasing $V_{\text {dcr_ref }}$ and decreasing $I_{d c i \_r e f}$ towards the nominal values. Therefore, $\alpha$ and $\gamma$ were reduced after reaching peak values of $16.1^{\circ}$ and $21.0^{\circ}$, respectively. Due to the SFC, $V_{d c r}$ and $\alpha$ were restored to their initial values. On the other hand, $I_{d c}$ and $\gamma$ remained at $464.7 \mathrm{~A}$ and $19.5^{\circ}$, respectively, continuously compensating for the increase in $P_{l i}$. On the contrary, in Case 2, $I_{d c}$ and $\gamma$ were restored to their initial values at approximately $t=$ $12 \mathrm{~s}$. This shows that the conventional SFC with PI controllers uses only the inverter-side generators to compensate for variations in $P_{l i}$. In Case 3, $V_{d c r}$ and $\alpha$ remained at their initial values, implying that the HVDC system and inverter-side generators did not contribute to rectifier-side GFR. A comparative analysis of the $\alpha$ - and $\gamma$-profiles was also performed when $P_{l r}$ increased at $t=35 \mathrm{~s}$. Both $\alpha$ and $\gamma$ were maintained within acceptable ranges (i.e., $5^{\circ} \leq \alpha \leq 135^{\circ}$ and $5^{\circ} \leq \gamma \leq 90^{\circ}$ [37]). This confirms that the proposed strategy ensures normal operation (i.e., not a saturated response) of HVDC converters.

Fig. 11 represents the corresponding profiles of $\Delta P_{d c i}, \Delta P_{g i}$, and $\Delta P_{g r}$. In Case $1, \Delta P_{g i}$ and $\Delta P_{g r}$ increased by 0.15 pu (or, 
more accurately, by $0.16 \mathrm{pu}$ and $0.14 \mathrm{pu}$, respectively) when $\Delta P_{l i}$ or $\Delta P_{l r}$ increased by $0.30 \mathrm{pu}$, given the identical model parameters and controller gains of the rectifier- and inverterside generators. In other words, the LQG controller enabled the load demand variation to be shared between the generators in both-side grids, reducing frequency deviation. Optimal control

(a)

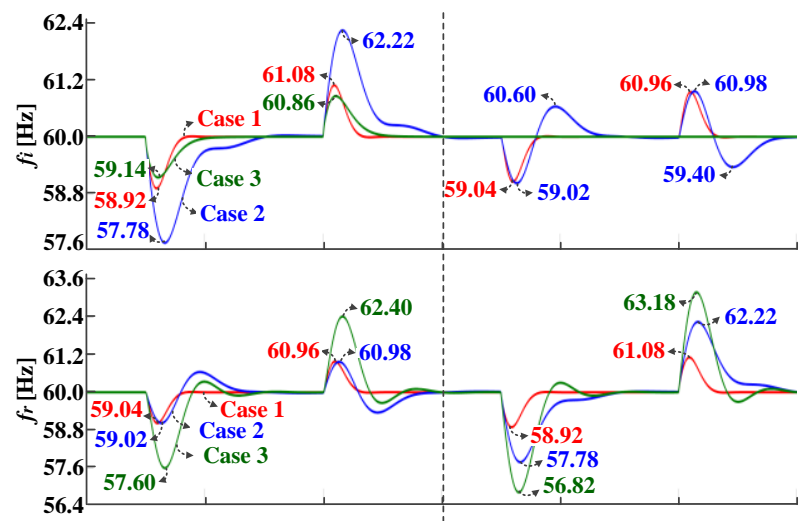

(c)

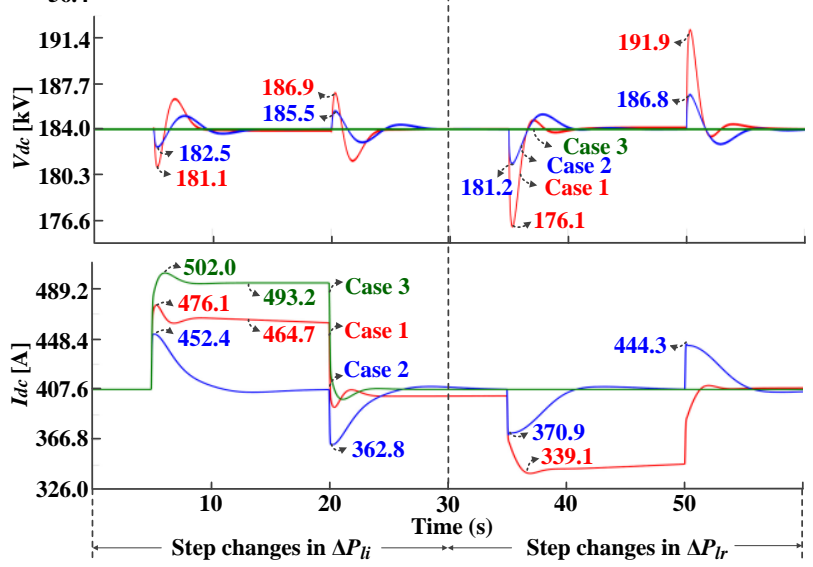

Fig. 9. Step responses to $\Delta P_{l i}\left(t=5^{+} \mathrm{s}\right)=\Delta P_{l r}\left(t=35^{+} \mathrm{s}\right)=0.3$ pu over $15 \mathrm{~s}$ with the proposed and conventional strategies: (a) $f_{i}$, (b) $f_{r}$, (c) $V_{d c}$, and (d) $I_{d c}$.

(a)

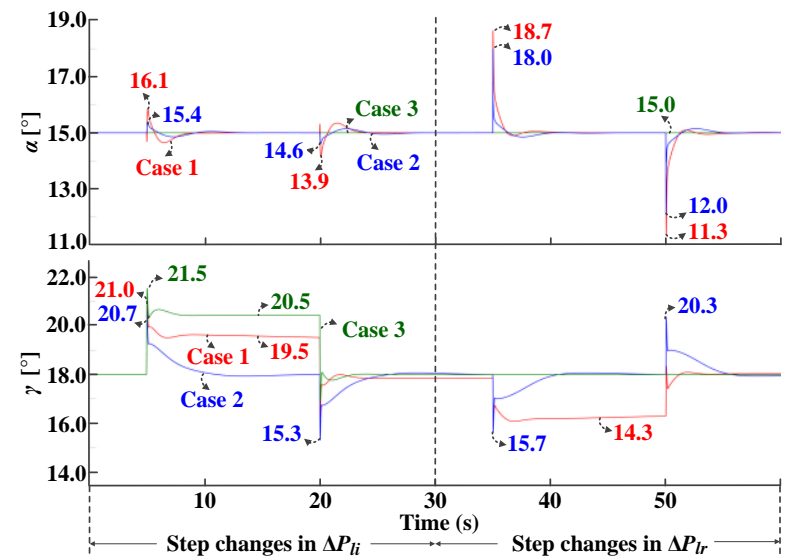

Fig. 10. Corresponding variations in the (a) firing and (b) extinction angles.

TABLE IV. COMPARISONS OF THE STEP RESPONSE TEST RESUlTS

\begin{tabular}{c|cccccc}
\hline \multirow{2}{*}{$\begin{array}{c}\text { Maximum } \\
\text { variations }\end{array}$} & \multicolumn{2}{|c}{ Case 1 } & \multicolumn{2}{c}{ Case 2 } & \multicolumn{2}{c}{ Case 3 } \\
& Individual & Total & Individual & Total & Individual & Total \\
\hline \hline$\left|\Delta f_{i}\right|_{\max }[\mathrm{Hz}]$ & 1.08 & \multirow{2}{*}{3.16} & 2.22 & \multirow{2}{*}{4.44} & 0.86 & \multirow{2}{*}{4.04} \\
$\mid \Delta f_{r \mid \max }[\mathrm{Hz}]$ & 1.08 & & 2.22 & & 3.18 & \\
\hline$\left|\Delta P_{d c i}\right|_{\max }[\mathrm{pu}]$ & 0.17 & \multirow{2}{*}{0.34} & 0.10 & \multirow{2}{*}{0.20} & 0.23 & \multirow{2}{*}{0.46} \\
$\left|\Delta P_{d c r}\right|_{\max }[\mathrm{pu}]$ & 0.17 & & 0.10 & & 0.23 & \\
\hline$\left|\Delta P_{g i}\right|_{\max }[\mathrm{pu}]$ & 0.20 & \multirow{2}{*}{0.39} & 0.32 & \multirow{2}{*}{0.63} & 0.10 & \multirow{2}{*}{0.51} \\
$\left|\Delta P_{g r}\right|_{\max }[\mathrm{pu}]$ & 0.19 & & 0.31 & & 0.41 & \\
\hline
\end{tabular}

of the dc-link voltage and current was also achieved to transfer the increased power generation in both the transient and steady state. In contrast, the PI controllers in Case 2 caused the generators to compensate for the load variations that occurred principally on the same side of the HVDC system. For $\Delta P_{l i}(t=$ $\left.5^{+} \mathrm{s}\right)=0.30 \mathrm{pu}, \Delta P_{g r}$ initially increased by $0.10 \mathrm{pu}$ and then remained close to zero. Therefore, the HVDC system could only marginally contribute to the rectifier-side GFR, and only during the period of the transient state, resulting in larger deviations and overshooting of $f_{i}$ and $f_{r}$. In Case $3, \Delta P_{l i}\left(t=5^{+}\right.$s) $=0.3$ pu caused larger variations in $P_{g r}$ and $f_{r}$ than in $P_{g i}$ and $f_{i}$, which can be problematic when the rectifier-side grid includes critical loads and generators with limited capacities. For all cases, $\Delta P_{d c i}$ and $\Delta P_{d c r}$ changed faster than $\Delta P_{g i}$ and $\Delta P_{g r}$. This verifies the effectiveness of the inertia emulation and droop control in exploiting the fast response of the HVDC converters.

(a)

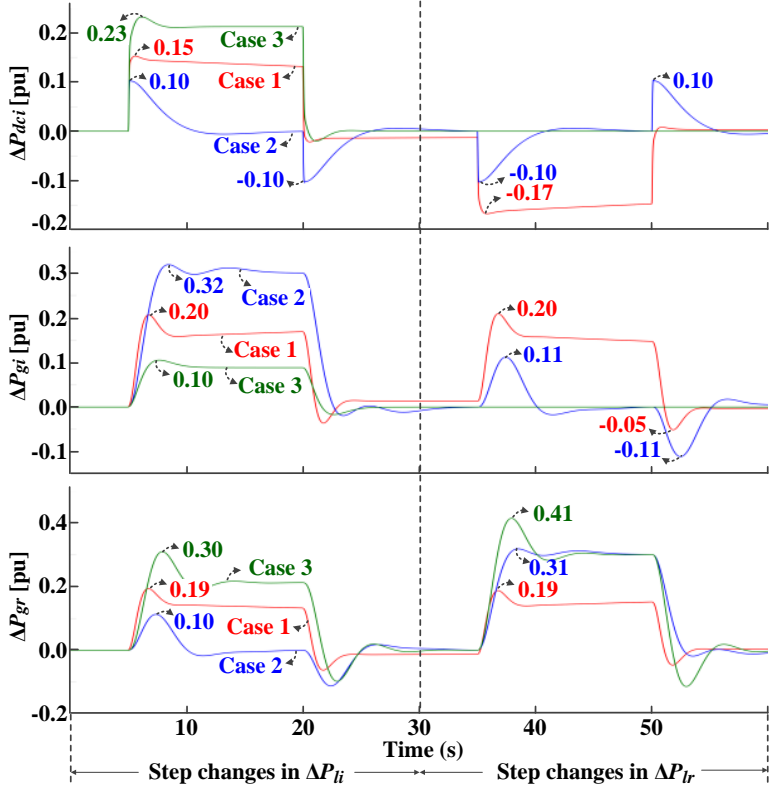

Fig. 11. Corresponding variations in the transferred and generated power: (a) $\Delta P_{d c i}$, (b) $\Delta P_{g i}$, and (c) $\Delta P_{g r}$.

\section{Comparisons of Continuous Load Demand Variations}

Additional case studies performed when $\Delta P_{l i}, \Delta P_{l r}$, and $\Delta P_{w}$ varied continuously, as shown in Fig. 7. Fig. 12 shows the corresponding profiles of $f_{i}, f_{r}, V_{d c}$, and $I_{d c}$, and Fig. 13 represents the profiles of $\alpha$ and $\gamma$. In Case 1, both $V_{d c}$ and $I_{d c}$ (and, consequently, $\alpha$ and $\gamma$ ) exhibited more rapid and larger variations than Cases 2 and 3. In other words, the proposed strategy enables more active and adaptive control of the HVDC system, further reducing $\Delta f$ and $\Delta P_{g}$ in both-side grids. Note that $\Delta V_{d c}, \Delta \alpha$, and $\Delta \gamma$ were maintained within acceptable ranges; the maximum variations were $2.5 \%, 0.7^{\circ}$, and $2.9^{\circ}$, respectively.

Table $\mathrm{V}$ lists the rms variations of $\Delta f$ and $\Delta P_{g}$, which were estimated as:

$$
\Delta f_{m m s}=\left(\sum_{m=1}^{M} \Delta f_{m}^{2} / M\right)^{1 / 2} \text { and } \Delta P_{g, r m s}=\left(\sum_{m=1}^{M} \Delta P_{g, m}^{2} / M\right)^{1 / 2} \text {, }
$$

where $m$ is the index of the measurement sample and $M$ is the total number of samples. In Case 1, the sum of $\Delta f_{i, r m s}$ and $\Delta f_{r, r m s}$ decreased by $57.3 \%$ and $53.1 \%$, compared to Cases 2 and 3 , respectively, verifying the effectiveness of the proposed control 
strategy in improving the GFR in both rectifier- and inverterside networks. In Case $1, \Delta P_{g, r m s}$ was $23.3 \%$ and $8.0 \%$ smaller than those in Cases 2 and 3, respectively, because the total variation in the load demand and WF power generation was shared among all generators on both sides. This implies that the proposed strategy can mitigate the operational requirements (e.g., the spinning reserve capacity) of the generators.

(a)

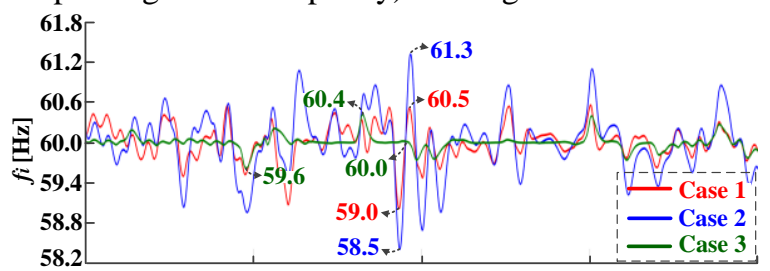

(b)

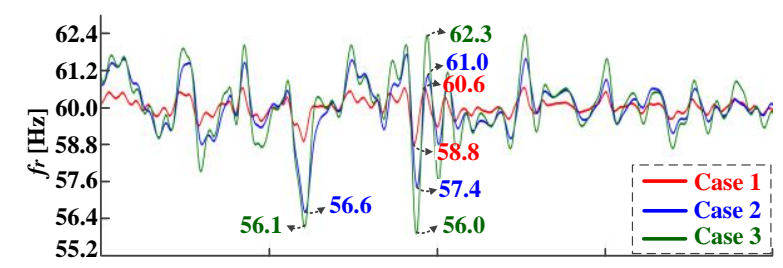

(c)

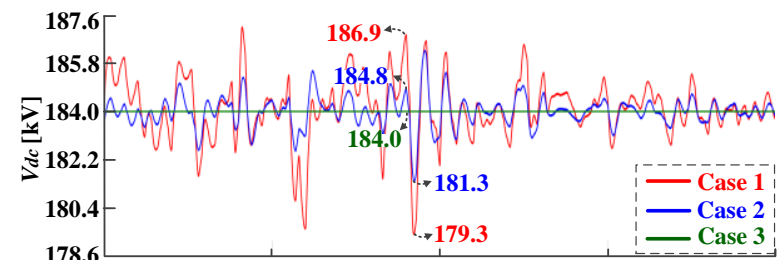

(d)

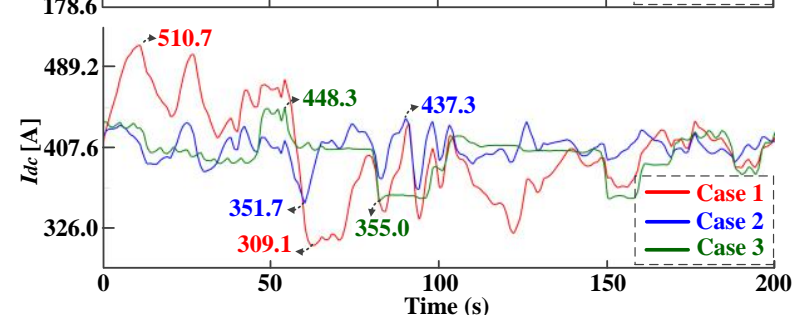

Fig. 12. Responses to continuous variations in $\Delta P_{l i}, \Delta P_{l r}$, and $\Delta P_{w}$ for the proposed and conventional strategies: (a) $f_{i}$, (b) $f_{r}$, (c) $V_{d c}$, and (d) $I_{d c}$.

(a)

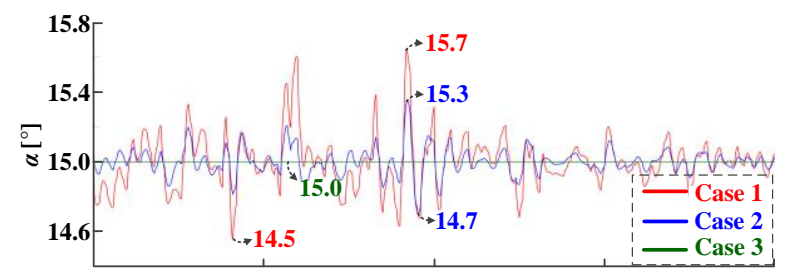

(b)

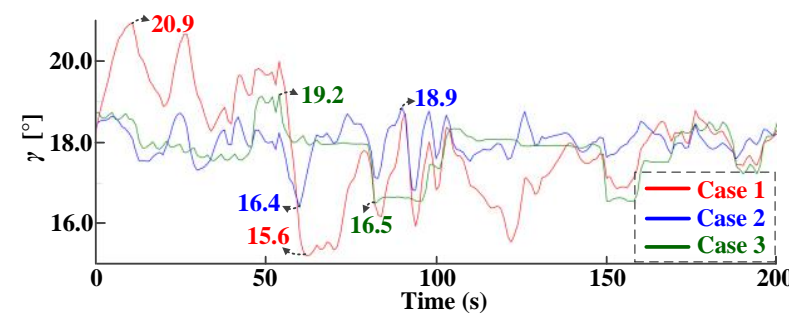

Fig. 13. Corresponding variations in the (a) firing and (b) extinction angles.

TABLE V. COMPARISONS OF THE CONTINUOUS RESPONSE TEST RESUltS

\begin{tabular}{c|cccccc}
\hline \multirow{2}{*}{$\Delta f_{r m s}$ and $\Delta P_{r m s}$} & \multicolumn{2}{|c}{ Case 1 } & \multicolumn{2}{c}{ Case 2 } & \multicolumn{2}{c}{ Case 3 } \\
& Individual & Total & Individual & Total & Individual & Total \\
\hline \hline$\Delta f_{i, r m s}[\mathrm{~Hz}]$ & 0.25 & \multirow{2}{*}{0.53} & 0.44 & \multirow{2}{*}{1.24} & 0.10 & \multirow{2}{*}{1.13} \\
$\Delta f_{r, r m s}[\mathrm{~Hz}]$ & 0.28 & & 0.80 & & 1.03 & \\
\hline$\Delta P_{g i, r m s}[\mathrm{pu}]$ & 0.11 & \multirow{2}{*}{0.23} & 0.08 & \multirow{2}{*}{0.30} & 0.02 & \multirow{2}{*}{0.25} \\
$\Delta P_{g r, r m s}[\mathrm{pu}]$ & 0.12 & & 0.22 & & 0.23 & \\
\hline
\end{tabular}

E. Proposed Strategy Performance under Various Conditions

TABLE VI. STEP RESPONSES FOR DifFERENT VALUES OF LQG PARAMETER $\mathbf{Q}$

\begin{tabular}{ccc|ccc}
\hline \multicolumn{3}{c|}{ Frequency $[\mathrm{Hz}]$} & \multicolumn{3}{c}{ HVDC-link voltage $[\mathrm{kV}]$} \\
\hline$\left|\Delta f_{i}\right|_{\max }$ & $\left|\Delta f_{r}\right|_{\max }$ & Total & $\left|\Delta V_{d c}\right|_{\max }$ for $\Delta P_{l i}$ & $\left|\Delta V_{d c}\right|_{\max }$ for $\Delta P_{l r}$ \\
0.96 & 0.96 & 1.92 & \multicolumn{2}{c|}{0.7} & \multicolumn{3}{c}{2.0} \\
\hline \hline \multicolumn{3}{c|}{ Transferred power $[\mathrm{pu}]$} & \multicolumn{3}{c}{ Generated power [pu] } \\
\hline$\left|\Delta P_{d c i}\right| \max$ & $\left|\Delta P_{d c r}\right|_{\max }$ & Total & $\left|\Delta P_{g i}\right|_{\max }$ & $\left|\Delta P_{g r}\right|_{\max }$ & Total \\
0.16 & 0.16 & 0.32 & 0.18 & 0.16 & 0.34 \\
\hline
\end{tabular}

TABLE VII. CONTINUOUS RESPONSE RESUlTS UNDER DIFFERENT INERTIAL RESPONSE AND DROOP CONTROL CONDITIONS

\begin{tabular}{|c|c|c|c|c|c|c|c|}
\hline \multirow{2}{*}{\multicolumn{2}{|c|}{$\Delta f_{r m s}$ and $\Delta P_{r m s}$}} & \multicolumn{2}{|c|}{ Case 1} & \multicolumn{2}{|c|}{ Case 2} & \multicolumn{2}{|c|}{ Case 3} \\
\hline & & Individual & Total & Individual & Total & Individual & Total \\
\hline \multirow{4}{*}{$\mathrm{a}$} & 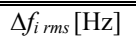 & 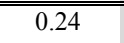 & \multirow{2}{*}{0.52} & 0.53 & \multirow{2}{*}{1.47} & 0.11 & \multirow{2}{*}{1.14} \\
\hline & $\Delta f_{r r m s}[\mathrm{~Hz}]$ & 0.28 & & 0.94 & & 1.03 & \\
\hline & $\Delta P_{\text {gi rms }}[\mathrm{pu}]$ & 0.11 & \multirow{2}{*}{0.23} & 0.09 & \multirow{2}{*}{0.32} & 0.02 & \multirow{2}{*}{0.25} \\
\hline & $\Delta P_{\text {gr rms }}[\mathrm{pu}]$ & 0.12 & & 0.23 & & 0.23 & \\
\hline \multirow{4}{*}{$\mathrm{b}$} & 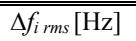 & 0.25 & \multirow{2}{*}{0.53} & 0.37 & \multirow{2}{*}{1.38} & $\begin{array}{l}0.10 \\
\end{array}$ & \multirow{2}{*}{1.13} \\
\hline & $\Delta f_{r r m s}[\mathrm{~Hz}]$ & 0.28 & & 1.01 & & 1.03 & \\
\hline & $\Delta P_{\text {gi rms }}[\mathrm{pu}]$ & 0.11 & \multirow{2}{*}{0.23} & 0.08 & \multirow{2}{*}{0.31} & 0.02 & \multirow{2}{*}{0.25} \\
\hline & $\Delta P_{g r} r m s[\mathrm{pu}]$ & 0.12 & & 0.23 & & 0.23 & \\
\hline
\end{tabular}

\begin{tabular}{c|cccccc}
\multicolumn{4}{c}{ TABLE VIII. CONTINUOUS RESPONSE RESUlTS FOR THE BENCHMARK MODEL } \\
\hline \multirow{2}{*}{$\Delta f_{r m s}$ and $\Delta P_{r m s}$} & \multicolumn{2}{|c}{ Case 1 } & \multicolumn{2}{c}{ Case 2 } & \multicolumn{2}{c}{ Case 3 } \\
& Individual & Total & Individual & Total & Individual & Total \\
\hline \hline$\Delta f_{i, r m s}[\mathrm{~Hz}]$ & 0.24 & \multirow{2}{*}{0.51} & 0.44 & \multirow{2}{*}{1.24} & 0.07 & \multirow{2}{*}{1.11} \\
$\Delta f_{\text {r,rms }}[\mathrm{Hz}]$ & 0.27 & & 0.80 & & 1.04 & \\
\hline$\Delta P_{\text {gi,rms }}[\mathrm{pu}]$ & 0.11 & \multirow{2}{*}{0.23} & 0.08 & \multirow{2}{*}{0.30} & 0.02 & \multirow{2}{*}{0.25} \\
$\Delta P_{\text {gr, rms }}[\mathrm{pu}]$ & 0.12 & & 0.22 & & 0.23 & \\
\hline
\end{tabular}

TABle IX. STEP Response Results For the Belo Monte HVDC System

\begin{tabular}{c|cc|cc|cc}
\hline Maximum & \multicolumn{2}{|c|}{ Case 1 } & \multicolumn{2}{|c|}{ Case 2 } & \multicolumn{2}{|c}{ Case 3 } \\
variations & Individual & Total & Individual & Total & Individual & Total \\
\hline \hline$\left|\Delta f_{i}\right|_{\max }[\mathrm{Hz}]$ & 1.26 & 2.22 & 2.40 & 4.56 & 0.86 & \\
$\left|\Delta f_{r}\right|_{\max }[\mathrm{Hz}]$ & 0.96 & & 2.16 & & 3.18 & \\
\hline$\left|\Delta \mathrm{V}_{d c}\right|_{\max }[\mathrm{kV}]$ & $29.6\left(3.7 \times 10^{-2} \mathrm{pu}\right)$ & $11.2\left(1.4 \times 10^{-2} \mathrm{pu}\right)$ & $0.0(0.0 \mathrm{pu})$ \\
\hline
\end{tabular}

TABle X. Continuous ResPonse Results for the Belo Monte Model

\begin{tabular}{c|cc|cc|cc}
\hline $\begin{array}{c}\text { Maximum } \\
\text { variations }\end{array}$ & \multicolumn{2}{|c|}{ Case 1 } & \multicolumn{2}{|c|}{ Case 2 } & \multicolumn{2}{|c}{ Case 3 } \\
\hline \hline$\Delta f_{i, r m s}[\mathrm{~Hz}]$ & 0.24 & 0.49 & 0.42 & 1.22 & 0.10 & 1.13 \\
$\Delta f_{t, r m s}[\mathrm{~Hz}]$ & 0.25 & & 0.80 & & 1.03 & \\
\hline$\Delta V_{d c, r m s}[\mathrm{kV}]$ & \multicolumn{2}{|c|}{$6.8\left(8.5 \times 10^{-3} \mathrm{pu}\right)$} & $2.3\left(2.9 \times 10^{-3} \mathrm{pu}\right)$ & $0.0(0.0 \mathrm{pu})$ \\
\hline
\end{tabular}

The case studies discussed in Section IV-C were repeated to analyze the performance of the proposed strategy using different values of the LQG parameters, particularly the weighting coefficients of $\mathbf{Q}$ (see (40)). Table VI shows the results of the step response test of the HVDC system when the weighting coefficients were increased 10 -fold compared to the original values used in Section IV-C. The proposed strategy decreased the variation in both frequency and dc-link voltage, thereby enhancing the transient stability of both the HVDC system and the interfacing grids. Moreover, when we increased the weighting coefficients assigned to states $\Delta f_{i}$ and $\Delta f_{r}$ in $\mathbf{X}_{\mathbf{E}}(t)$, the maximum frequency deviation gradually decreased. This implies that the proposed strategy allows the HVDC system to support the rectifier-side GFR more intensively than the inverter-side GFR, or vice versa, depending on the wind generation capacity and load composition, for example. 
In addition, the case studies in Section IV-D were repeated to analyze the performance of the proposed strategy compared to the conventional strategies, under various inertia emulation and droop control conditions. Table VII shows the corresponding results. Moreover, the case studies were carried out using the CIGRE benchmark model [21] with a rated power of 1,000 MW and a rated voltage of $500 \mathrm{kV}$; Table VIII shows the numerical results. The proposed strategy was also tested using the Belo Monte HVDC system [39], which has a long transmission line with an equivalent inductance of $1,892 \mathrm{mH}$, which is approximately 9.46- and 3.17-fold those of the Jeju-Haenam and CIGRE systems, respectively. Tables IX and $\mathrm{X}$ summarize the case study results with respect to $\Delta f_{i}, \Delta f_{r}$, and $\Delta V_{d c}$ for the step and continuous response tests, respectively.

Under all conditions, the proposed strategy successfully reduced frequency deviations by optimally coordinating the HVDC converters and generators, resulting in relatively small variations in the dc-link voltage. The case study results also confirm that the effectiveness of the proposed strategy is attributable to the inherent capability of HVDC converters to respond faster than conventional generators, rather than the inductance itself of the dc link and dc harmonic filters.

\section{F. Relative Lifetime Analysis of the Proposed Strategy}

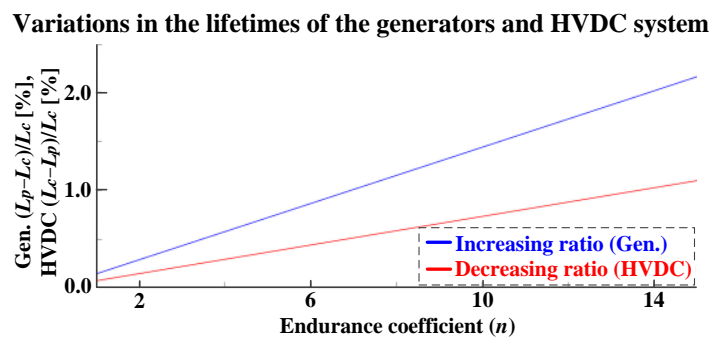

Fig. 14. Increasing and decreasing lifetime ratios of the generators and HVDC system, respectively, for Case 1 and Case 3 .

In this paper, an inverse power modeling (IPM) method [40]-[42] was used to estimate the lifetimes of the HVDC system and generators when the proposed and conventional strategies were applied. In particular, $\Delta V_{d c}, \Delta f_{i}$, and $\Delta f_{r}$ were considered for lifetime estimation, because both strategies only marginally affect the ac voltage and the dc link has a zero-frequency voltage and current. Consequently, the IPM methods for the HVDC system and generators were established as:

$$
\frac{L_{P, H V D C}}{L_{C, H V D C}}=\left(\frac{V_{d c, r m s, P}}{V_{d c, r m s, C}}\right)^{-n_{V}} \text { and } \frac{L_{P, G e n}}{L_{C, G e n}}=\left(\frac{f_{i, m s, P}+f_{r, m s s, P}}{f_{i, m s, C}+f_{r, m s, C}}\right)^{-n_{f}} \text {, }
$$

where $L_{P}$ and $L_{C}$ are the lifetimes of the proposed and conventional strategies, respectively. In (46), $n_{V}$ and $n_{f}$ are the endurance coefficients for $\Delta V_{d c}$ and $\Delta f$, respectively. For simplicity, $n_{V}$ and $n_{f}$ were set to be equal (i.e., $n_{V}=n_{f}=n$ ) and were varied from 1 to 15 [40]-[42]. The IPM methods were applied to the case study results shown in Fig. 12. In Fig. 14, the red line indicates the decreasing ratio [i.e., $\left(L_{C, H V D C}-\right.$ $\left.\left.L_{P, H V D C}\right) / L_{C, H V D C}\right]$ of the lifetime of the HVDC system for Case 1 to that for Case 3 over the value of $n$. Similarly, the blue line represents the increasing ratio [i.e., $\left(L_{P, G e n}-L_{C, G e n}\right) / L_{C, G e n}$ ] of the lifetime of the generators for Case 1 to that for Case 3. Note that, for the conventional strategies, the values of $\left(\Delta f_{i, r m s}+\Delta f_{r, r m s}\right)$ and $\Delta V_{d c, r m s}$ in Case 3 are lower than those in Case 2. Fig. 14 shows that the increasing ratios were greater than the decreasing ratios. This implies that the costs imposed by an increase in voltage insulation stress on the HVDC system can be sufficiently compensated by the savings attributable to reduced operating stress on the generators.

\section{CONCLUSIONS}

This paper has proposed a new control strategy for an LCC HVDC system, in which the dc-link voltage and current were optimally regulated to improve the GFR in both the rectifierand inverter-side networks under normal operating conditions. A new small-signal model of an HVDC system was developed, verified via comparison with a comprehensive model, and integrated with feedback loops for inertia emulation and droop control. An LQG controller including a Kalman filter was also designed for optimal SFC while mitigating conflict between the droop controllers of the HVDC converters. An eigenvalue analysis was then conducted, focusing on the effects of the dc-link parameters and droop coefficients on the performance of the proposed strategy. Case studies were also carried out using models of a real LCC HVDC system and a CIGRE benchmark system, where the proposed strategy decreased the maximum frequency variation by $28.8 \%$ and the rms variation by $57.3 \%$ for stepwise and continuous load demand variations, respectively, compared to the conventional strategies. The proposed strategy enabled the total load demand variation to be shared between the generators in both-side grids, reducing the power generation variation by $23.3 \%$. The proposed strategy was effective under various conditions of the LQG parameters, the system specifications, and the inertia emulation and droop control approaches. Further work will focus on the analysis of the proposed strategy under abnormal, contingent conditions of the HVDC system and ac networks (e.g., generator tripping, short-circuit faults, and commutation failures) to ensure frequency and voltage stability during and after contingency.

\section{APPENDIX}

The coefficients used in (5)-(18) are defined as: $a_{1 x}=3 \sqrt{2} N V_{l x}\left(\pi T R_{x}\right)^{-1}, a_{2 x}=3 X_{c x} N \pi^{-1}, a_{3 x}=\sqrt{2} X_{c x} /\left(V_{l x} / T R_{x}\right)$, $a_{4 x}=3 N\left(V_{l x}\right)^{2} / 4 \pi X_{c x}\left(T R_{x}\right)^{2}, a_{5 x}= \pm H_{d c x} 0^{-1}$,

$b_{1 x}=-a_{1 x} \sin \beta_{0}, b_{2 x}=-\sin \beta_{0}+\sin \left(\beta_{0}+\mu_{x 0}\right)$,

$b_{3 x}=\sin \left(\beta_{0}+\mu_{x 0}\right), b_{4 x}=a_{5 x}\left\{-2 \sin \left(2 \beta_{0}\right)+2 \sin 2\left(\beta_{0}+\mu_{x 0}\right)\right\}$,

$b_{5 x}=a_{5 x} 2 \sin 2\left(\beta_{0}+\mu_{x 0}\right)$,

$c_{1 r}=\left(b_{1 r} b_{3 r} V_{d c r 0}+a_{2 r} b_{3 r} b_{4 r}-a_{2 r} b_{2 r} b_{5 r}-a_{4 r} a_{5 r} b_{1 r}\right)$,

$c_{2 r}=\left(a_{2 r} b_{3 r} I_{d c r 0}-b_{3 r} V_{d c r 0}+a_{4 r} b_{5 r}\right)$,

$c_{1 i}=V_{d c i 0}-a_{2 i} I_{d c i 0}, \quad c_{2 i}=b_{2 i} b_{5 i}-b_{3 i} b_{4 i}-b_{1 i} b_{3 i} I_{d c i 0}$,

where the letter set of $(x, \beta, H)$ corresponds to $(r, \alpha, V)$ and $(i, \gamma$, I) for the rectifier and inverter, respectively. The coefficients for the state-space model (34) and (35) are represented as:

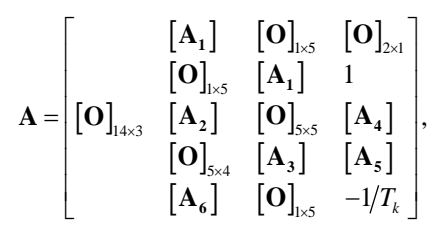




$$
\begin{aligned}
& {\left[\mathbf{A}_{1}\right]=\left[\begin{array}{ll}
1 & {[\mathbf{O}]_{1 \times 4}} \\
0 & {[\mathbf{O}]_{1 \times 4}}
\end{array}\right],} \\
& {\left[\mathbf{A}_{4}\right]=\left[\begin{array}{l}
{[\mathbf{O}]_{4 \times 1}} \\
1 / k_{i} T_{i} V_{d c i 0}
\end{array}\right],} \\
& {\left[\mathbf{A}_{2}\right]=} \\
& \begin{array}{c}
-D_{i} / M_{i} \\
-1 / R_{g i} T_{g i} \\
0 \\
-V_{i} D_{i} / M_{i} T_{f i} \\
-1 / R_{i} T_{i} V_{d c i 0}
\end{array} \\
& \begin{array}{c}
0 \\
-1 / T_{g i} \\
1 / T_{t i} \\
0 \\
0
\end{array} \\
& 1 / M_{i} \quad 0 \\
& 0 \quad 1 / M_{i} \\
& 0 \\
& -1 / T_{t i} \\
& 0 \quad 0 \\
& V_{i} / M_{i} T_{f i} \quad-1 / T_{f i} \quad V_{i} / M_{i} T_{f i} \\
& \begin{array}{lll}
0 & -1 / T_{i} V_{d c i 0} & -1 / T_{i}
\end{array} \\
& {\left[\mathbf{A}_{\mathbf{6}}\right]=\left[\begin{array}{ll}
{[\mathbf{O}]_{1 \times 4}} & -2 R / T_{k}
\end{array}\right],} \\
& -D_{r} / M_{r} \\
& -1 / R_{g r} T_{g r} \\
& \begin{array}{cc}
0 & -1 / M \\
-1 / T_{g r} \\
1 / T_{r r}
\end{array} \\
& {\left[\mathbf{A}_{3}\right]=} \\
& 0 \\
& \begin{array}{cc}
-V_{r} / M_{r} T_{f r r} & -V_{r} D_{r} / M_{r} T_{f r} \\
0 & 1 / R_{r} T_{r} I_{d c r 0}
\end{array} \\
& -1 / M_{r} \\
& 0 \\
& \begin{array}{l}
0 \\
0
\end{array} \\
& T_{t r} \\
& -1 / T \quad 0 \\
& \begin{array}{cc}
-1 / T_{t r} & 0 \\
V_{r} / M_{r} T_{f r} & -1 / T_{f r} \\
0 & 1 / T_{I}
\end{array} \\
& 0
\end{aligned}
$$

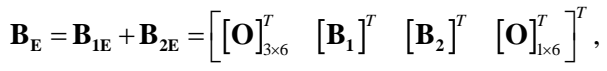

$$
\begin{aligned}
& {\left[\mathbf{B}_{1}\right]=\left[\begin{array}{lll}
{[\mathbf{O}]_{1 \times 4}} & -1 / M_{i} & 0 \\
1 / T_{g i} & 0 & {[\mathbf{O}]_{\times 4}} \\
& {[\mathbf{O}]_{\times 6}} & \\
{[\mathbf{O}]_{1 \times 4}} & -V_{i} / M_{i} T_{f i} & 0 \\
{[\mathbf{O}]_{\ltimes \times 2}} & 1 / T_{i} V_{d c r 0} & {[\mathbf{O}]_{\times \times 3}}
\end{array}\right],} \\
& {\left[\mathbf{B}_{2}\right]=\left[\begin{array}{lll}
{[\mathbf{O}]_{1 \times 4}} & 0 & -1 / M_{r} \\
0 & 1 / T_{g r} & {[\mathbf{O}]_{1 \times 4}} \\
& {[\mathbf{O}]_{1 \times 6}} & \\
{[\mathbf{O}]_{1 \times 4}} & 0 & -V_{r} / M_{r} T_{f r} \\
{[\mathbf{O}]_{\times \times 3}} & 1 / T_{r} I_{d c r 0} & {[\mathbf{O}]_{\times \times 3}}
\end{array}\right]} \\
& \mathbf{C}_{\mathbf{E}}=\left[\begin{array}{lll}
{[\mathbf{O}]_{1 \times 3}} & 1 & {[\mathbf{O}]_{1 \times 10}} \\
{[\mathbf{O}]_{1 \times 8}} & 1 & {[\mathbf{O}]_{1 \times 5}} \\
{[\mathbf{O}]_{1 \times 13}} & 1 \\
{\left[\mathbf{C}_{\mathbf{1}}\right]} & {[\mathbf{O}]_{3 \times 10}}
\end{array}\right], \quad \text { and } \quad\left[\mathbf{C}_{\mathbf{1}}\right]=\mathbf{I}_{3 \times 3}, \quad \mathbf{D}_{\mathbf{E}}=[\mathbf{O}]_{6 \times 4}
\end{aligned}
$$

\section{REFERENCES}

[1] A. Ferrante et al., "The Mediterranean master plan consolidating a secure and sustainable electricity infrastructure in the Mediterranean region," in Proc. 2018 CIGRE, Paris, Aug. 2018, pp. 1-12.

[2] S. Favuzza et al., "New energy corridors in the Euro-Mediterranean area: the pivotal role of Sicily," Energies, vol. 11, no. 6, pp. 1-14, Jun. 2018.

[3] N. Anderson. (2016, Aug.). Shetland HVDC link project. Scottish and Southern Energy, Scotland. [Online]. Available: http://www.ssen-transmisson.co.uk/med ia/1514/shetland-hvdc-link-consultation-summary-booklet-august-2016.pdf

[4] D. Osborn. (2017, Apr.). MISO Transmission Planning Processes. Midcontinent Independent System Operator, Carmel, IN. [Online]. Available: https//www.cne.cl/wp-content/uploads/2017/04/Dale- Osborn.pdf

[5] R. Li et al., "Frequency control design for offshore wind farm grid with LCC-HVDC link connection," IEEE Trans. Power Electron., vol. 23, no. 3, pp. 1085-1092, May 2008.

[6] Z. Miao et al., "Wind farms with HVdc delivery in inertial response and primary frequency control," IEEE Trans. Energy Convers., vol. 25, no. 4, pp. 1171-1178, Dec. 2010.

[7] A. Yogarathinam et al., "Impact of inertia and effective short circuit ratio on control of frequency in weak grids interfacing LCC-HVDC and DFIG-based wind farms," IEEE Trans. Power Del., vol. 32, no. 4, pp. 2040-2051, Aug. 2017.

[8] L. Wang and M. Sa-Nguyen Thi, "Stability enhancement of a PMSG-based offshore wind farm fed to a multi-machine system through an LCC-HVDC link," IEEE Trans. Power Syst., vol. 28, no. 3, pp. 3327-3334, Aug. 2013.

[9] Y. Wen et al., "Enhancing frequency stability of asynchronous grids interconnected with HVDC links," IEEE Trans. Power Syst., vol. 33, no. 2, pp. 1800-1810, Mar. 2018.

[10] S. G. Vennelaganti et al., "New insights into coupled frequency dynamics of AC grids in rectifier and inverter sides of LCC-HVDC interfacing DFIG-based wind farms," IEEE Tran. Power Del., vol. 33, no. 4, pp. 1765-1776, Aug. 2018.

[11] S. P. Azad, R. Iravani, and J. E. Tate, "Damping inter-area oscillations based on a model predictive control (MPC) HVDC supplementary controller," IEEE Trans. Power Syst., vol. 28, no. 3, pp. 3174-3183, Aug. 2013.

[12] S. P. Azad et al., "Decentralized supplementary control of multiple LCC-HVDC links," IEEE Trans. Power Syst., vol. 31, no. 1, pp. 572-580, Jan. 2016.

[13] A. Gustafsson et al., "The new $525 \mathrm{kV}$ extruded HVDC cable system," ABB Grid Systems Technical Paper, pp. 1-8, Aug. 2014.

[14] M. Saltzer et al., "Surge and extended overvoltages testing of HVDC cable systems," in Proc. Int. Conf. Insulated Power Cables (Jicable' 17), Dunkerque, France, Nov. 2017, pp. 94-101.
[15] J. Zhu et al., "Inertia emulation control strategy for VSC-HVDC transmission systems," IEEE Trans. Power Syst., vol. 28, no. 2, pp. 1277-1287, May. 2013.

[16] A. Junyent-Ferr, Y. Pipelzadeh, and T. C. Green, "Blending HVDC-link energy storage and offshore wind turbine inertia for fast frequency response," IEEE Trans. Sustain. Energy, vol. 6, no. 3, pp. 1059-1066, Jul. 2015.

[17] D. Kwon et al., "Modeling and analysis of an LCC HVDC system using DC voltage control to improve transient response and short-term power transfer capability," IEEE Trans. Power Del., vol. 33, no. 4, pp. 1922-1933, Aug. 2018.

[18] Y. Xue et al., "Reactive power and AC voltage control of LCC HVDC system with controllable capacitors," IEEE Trans. Power Syst., vol. 32, no. 1, pp. 753764, Jan. 2017.

[19] C Karawita et al., "Multi-infeed HVDC interaction studies using small-signal stability assessment," IEEE Trans. Power Del., vol. 24, no. 2, pp. 910-918, Apr. 2009.

[20] D. Yoon et al., "Smart operation of HVDC systems for large penetration of wind energy resources," IEEE Trans. Smart Grid, vol. 4, no. 1, pp. 359-366, Mar. 2013.

[21] H. Atighechi et al., "Dynamic Average-Value Modeling of CIGRE HVDC Benchmark System," IEEE Trans. Power Del., vol. 29, no. 5, pp. 2046-2054, Oct. 2014.

[22] G. Morin et al., "Modeling of the hydro-Quebec - New England HVDC system and digital controls with EMTP," IEEE Trans. Power Del., vol. 8, no. 2, pp. 559-566, Apr. 1993.

[23] F. Kong et al., "Development of a novel protection device for bipolar HVDC transmission lines," IEEE Trans. Power Del., vol. 29, no. 5, pp. 2270-2278, Oct. 2014.

[24] H. T. Wang et al., "Stability mechanism analysis of HVDC control system for power system restoration using HVDC," in Proc. 4th Int. Conf. Electric Utility Deregulation Restructuring Power Technol., Weihai, China, Jul. 2011, pp. 433437.

[25] H. Liu and J. Sun, "Modeling and analysis of dc-link harmonic instability in LCC HVDC systems," in Proc. IEEE 14th Workshop on Control and Modeling for Power Electronics (COMPEL), Salt Lake City, UT, Jun. 2013, pp. 1-9.

[26] M. Vasiladiotis and A. Rufer, "Dynamic analysis and state feedback voltage control of single-phase active rectifiers with dc-link resonant filters," IEEE Trans. Power Electron., vol. 29, no. 10, pp. 5620-5633, Oct. 2014.

[27] S. M. Muyeen et al., "Operation and control of HVDC-connected offshore wind farm," IEEE Trans. Sustain. Energy, vol. 1, no. 1, pp. 30-37, Apr. 2010.

[28] P. Kundur, Power System Stability and Control, Toronto, ON, Canada: McGraw-Hill, 1994, pp. 463-626.

[29] R. E. Kalman, "A new approach to linear filtering and prediction problems," J.Basic Eng., vol. 82, no. 1, pp. 35-45, Mar. 1960.

[30] Y. Song and C. Breitholtz, "Nyquist stability analysis of an AC-grid connected VSC-HVDC system using a distributed parameter DC cable model," IEEE Trans. Power Del., vol. 31, no. 2, pp. 898-907, Apr. 2016.

[31] M. K. Bucher et al., "Fault current interruption in multiterminal HVDC networks," IEEE Trans. Power Del., vol. 31, no. 1, pp. 87-95, Feb. 2016.

[32] T. K. Vrana et al., "The CIGRE B4 DC grid test system", Electra, vol. 270, pp. 10-19, Oct. 2013.

[33] F. Kong et al., "Development of a novel protection device for bipolar HVDC trans- mission lines," IEEE Trans. Power Del., vol. 29, no. 5, pp. 2270-2278, Oct. 2014.

[34] G. Jang et al., "Novel reactive-power-compensation scheme for the Jeju-Haenam HVDC system," IEE Proc.- Gener. Transm. Distrib., vol. 152, pp. 514-520, Jul. 2005.

[35] C. K. Kim et al., "Transient performance of Cheju-Haenam HVDC system," in Proc. IEEE Power Eng. Soc. Summer Meeting, Vancouver, BC, Jul. 2001, pp. 343-348.

[36] S. Hwang et al., "Evaluation of STATCOM capacity on transient stability in Jeju-island system with HVDC and wind farms," in Proc. 9th International Conf. Power Electronics and ECCE Asia (ICPE-ECCE Asia), Seoul, Jul. 2015, pp. 367-372.

[37] D. Kwon et al., "Modeling of HVDC System to improve estimation of transient DC current and voltages for AC line-to-ground fault - an actual case study in Korea," Energies, vol. 10, no. 10, pp. 1-18, Oct. 2017.

[38] Fast Response Regulation Signal, PJM [Online]. Available: http://www.pjm.com/markets-and-operations/ancillary-services/mkt-based-reg ulation/fast-response-regulation-signal.aspx

[39] D. S. Carvalho et al., "Final project planning conception for the first $800 \mathrm{kV}$ HVDC link of Belo Monte," in Proc. 2014 CIGRE, Paris, Aug. 2014, pp. 1-9.

[40] P. Morshuis et al., "Stress conditions in HVDC equipment and routes to in service failure," IEEE Trans. Dielectr. Electr. Insul., vol. 22, no. 1, pp. 81-91, Feb. 2015.

[41] P. Maussion et al., "Lifespan and aging modeling methods for insulation systems in electrical machines: A survey," in Proc. IEEE Workshop Elect. Mach. Des. Control Diagnosis, Torino, Mar. 2015, pp. 279-288.

[42] V. I. J. Kokko, "Ageing due to thermal cycling by start and stop cycles in lifetime estimation of hydroelectric generator stator windings," in Proc. IEEE International Electric Machines \& Drives Conference (IEMDC), Marseille, May 2011, pp. 318-323. 
Do-Hoon Kwon (S'15) received the B.S., M.S., and Ph.D. degrees in electrical engineering from Seoul National University, Seoul, South Korea, in 2010, 2012, and 2018, respectively. He is currently a Senior Researcher in the Smart Power Grid Research Center, Korea Electrotechnology Research Institute (KERI), Uiwang, South Korea. His research interests include HVdc systems, energy management systems, and smart distribution systems.

Dr. Kwon was selected as a recipient of the Best Reviewer for the IEEE TRANSACTIONS ON SMART GRID in 2017.

Young Jin Kim (S'14-M'15) Young-Jin Kim (Member, IEEE) received the B.S. and M.S. degrees in electrical engineering from Seoul National University in 2007 and 2010, respectively, and the Ph.D. degree in electrical engineering from the Massachusetts Institute of Technology in 2015. He worked with Korea Electric Power Corporation as a Power Transmission and Distribution System Engineer from 2007 to 2011. He was also a Visiting Scholar with the Catalonia Institute for Energy Research in 2014, and a Postdoctoral Researcher with Center for Energy, Environmental, and Economic Systems Analysis, Energy Systems Division, Argonne National Laboratory from 2015 to 2016. He joined the faculty of the Pohang University of Science and Technology, where he is currently an Associate Professor with the Department of Electrical Engineering. His research fields of interest include distributed generators, renewable energy resources, and smart buildings.

Dr. Kim is a recipient of the Best Reviewer for the IEEE TRANSACTIONS ON SMART GRID in 2019. He is an Editor of the IEEE TRANSACTIONS ON SMART GRID.

Oriol Gomis-Bellmunt (S'05-M'07-SM'12) received the degree in industrial engineering from the School of Industrial Engineering of Barcelona (ETSEIB), Technical University of Catalonia (UPC), Barcelona, Spain, in 2001 and the $\mathrm{Ph} . D$. degree in electrical engineering from the UPC in 2007. In 1999, he joined Engitrol S.L. where he worked as Project Engineer in the automation and control industry. Since 2004, he has been with the Electrical Engineering Department, UPC where he is a Professor and participates in the CITCEA-UPC Research Group. Since 2020, he is an ICREA Academia researcher. His research interests include the fields linked with electrical machines, power electronics, and renewable energy integration in power systems. 